\title{
Primary Culture of Identified Neurons from the Visual Cortex of Postnatal Rats
}

\author{
James E. Huettner and Robert W. Baughman \\ Department of Neurobiology, Harvard Medical School, Boston, Massachusetts 02115
}

We have examined the properties of neurons from the visual cortex of postnatal Long Evans rats in dissociated cell culture. Visual cortex from rat pups 1-15 d old was subjected to enzymatic and mechanical dissociation to yield a suspension of single cells. Neurons plated onto collagen or a feeder layer of astrocytes rapidly extended processes and survived for 4-10 weeks. Antisera to glutamic acid decarboxylase, choline acetyltransferase, and vasoactive intestinal polypeptide stained $22 \pm 2,2.3 \pm$ 0.3 , and $2.4 \pm 0.2 \%$ of all neurons, respectively, suggesting that different neuronal classes survived roughly in proportion to their number in vivo.

In order to study a particular identified class of cortical neurons, we prelabeled cells in vivo by retrograde transport of a fluorescent tracer. Neurons in layer $V$ of visual cortex that project to the superior colliculus were labeled after injecting fluorescent latex microspheres into the colliculus. Retrogradely labeled neurons were readily identified immediately after dissociation and throughout the period in vitro. After 2 weeks in culture, labeled cells exhibited many ultrastructural features characteristic of pyramidal neurons in vivo.

Intracellular recording techniques were used to evaluate the response properties of labeled layer $\mathrm{V}$ neurons, as well as other, unlabeled neurons, to excitatory amino acid agonists and antagonists. Glutamate and aspartate - as well as the synthetic agonists $N$-methyl-D-aspartate (NMDA), kainate, and quisqualate-excited every cortical neuron tested. The antagonist 2-amino-5-phosphonovaleric acid had no effect on responses to quisqualate and kainate but completely blocked depolarizations due to NMDA and aspartate and reduced depolarizations elicited by low concentrations of glutamate. Kynurenic acid, piperidine dicarboxylic acid, and $\gamma$-D-glutamylglycine antagonized responses to all 5 of the agonists. These results provide evidence that corticocollicular neurons in culture express both NMDAtype and non-NMDA receptors for excitatory amino acids.

The cerebral cortex is a laminated structure composed of many diverse neuronal cell types. In the visual cortex, each layer contains classes of neurons with characteristic morphology, visual response properties, and anatomical projection patterns (Gilbert, 1983; Peters, 1985). The projection from visual cortex to the superior colliculus, for example, arises from a population of pyramidal neurons in layer $\mathrm{V}$, while 2 separate groups of

\footnotetext{
Received Jan. 13, 1986; revised Mar. 14, 1986; accepted Mar. 27, 1986.

This work was supported by the Harvard University Society of Fellows and a National Science Foundation Predoctoral Fellowship (J.E.H.) and by NIH Grant EY03502 and the William F. Milton Fund (R.W.B.).

We wish to thank Sue McConnell, Bruce Bean, and Ken Jones for critical reading of the manuscript. We also thank J. Gagliardi for photography, H. Mekeel for thin sectioning, U. Dräger, J. Walsh, and F. Eckenstein for generously donating antibodies, and A. Burkhalter for providing fluorescent microspheres.

Correspondence should be addressed to James E. Huettner, Department of Neurobiology, Harvard Medical School, 25 Shattuck St., Boston, MA 02115.
}

Copyright (C) 1986 Society for Neuroscience $0270-6474 / 86 / 103044-17 \$ 02.00 / 0$ neurons in layer VI innervate the claustrum and the lateral geniculate nucleus (Gilbert and Kelly, 1975; LeVay and Sherk, 1981; Sefton et al., 1981). Neurons in each of these populations also possess axon collaterals that ramify within the visual cortex itself (Gilbert and Wiesel, 1979; Katz et al., 1984; Parnavelas et al., 1983). Although much is known about the morphology and receptive field properties of cells in visual cortex, it has been difficult to study the electrophysiological and biochemical characteristics of particular neuronal classes because of the inaccessibility of individual neurons within the intact brain. Information concerning the neurotransmitter(s) employed by specific populations of cortical neurons has come chiefly from immunocytochemical studies (Eckenstein and Thoenen, 1983; McDonald et al., 1982; Ribak, 1978; Schmechel et al., 1984; Somogyi et al., 1984) and from autoradiographic localization of neurons that accumulate radioactive transmitter candidates (Baughman and Gilbert, 1981; Chronwall and Wolff, 1980; Hamos et al., 1983). Several lines of evidence suggest that glutamate and aspartate may function as excitatory neurotransmitters in the cortex (Fonnum, 1984; Streit, 1984), while GABA is a strong candidate for the major inhibitory transmitter (Houser et al., 1984). Evidence for at least 3 different receptor sites for glutamate has been presented (Foster and Fagg, 1984; Watkins and Evans, 1981), but the role of each receptor type in excitatory synaptic transmission has not been established.
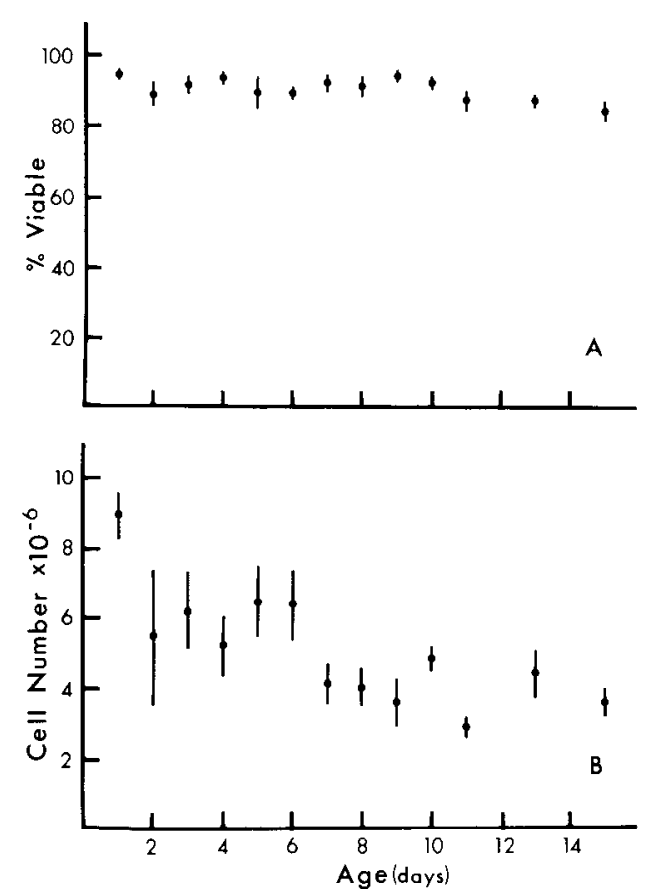

Figure 1. Percentage of viable cells $(A)$ and total number of freshly dissociated cells $(B)$ plotted as functions of the age of the donor animal. 

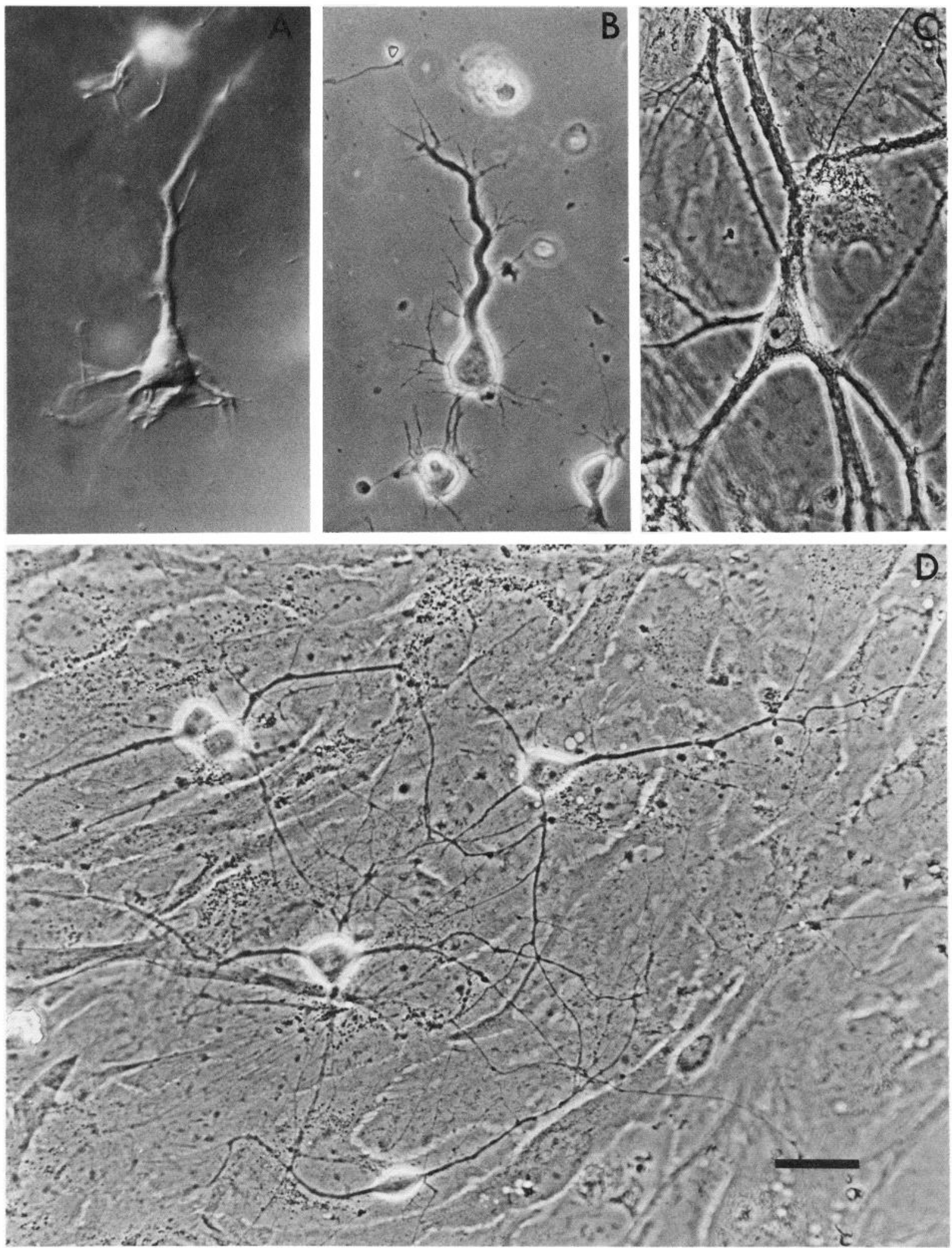

Figure 2. Dissociated neurons from the visual cortex of animals aged $3 \mathrm{~d}(D), 7 \mathrm{~d}(B), 8 \mathrm{~d}(A)$, and $15 \mathrm{~d}(C) . A$, Photomicrograph taken with Nomarski optics immediately after dissociation. $B-D$, Phase-contrast photomicrographs of neurons in culture for $3 \mathrm{hr}(B), 16 \mathrm{~d}(D)$, and $19 \mathrm{~d}(C)$. Bar, $30 \mu \mathrm{m}$. 

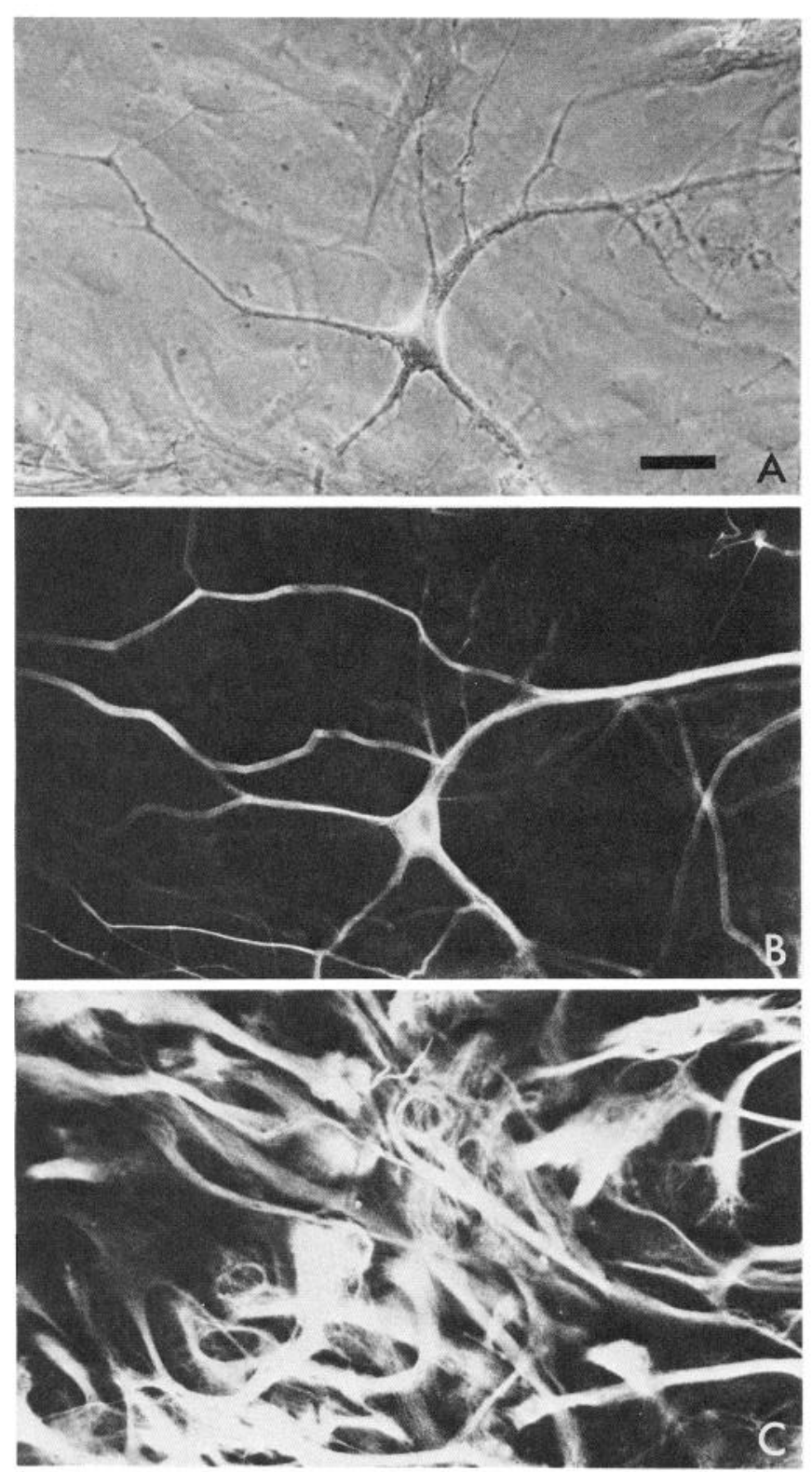

Figure 3. Immunofluorescence double-labeling of neurofilament-like $(B)$ and glial fibrillary acidic protein-like $(C)$ immunoreactivity. $A$, Phasecontrast photomicrograph of cells from a 7-d-old animal in vitro for 26 d. $B$, Same field stained for neurofilament-like immunoreactivity, FITClabeled second antibody. $C$, Same field as $A$ and $B$ stained for glial fibrillary acidic protein-like immunoreactivity, RITC-labeled second antibody. Bar, $40 \mu \mathrm{m}$.

Tissue culture of dissociated neurons has proven to be a useful technique for examining the function and development of cells from both the central and peripheral nervous systems (Fischbach and Nelson, 1977). Cells in culture are readily available for physiological recordings, and their fluid environment can be controlled. In the case of a heterogeneous structure such as the cortex, however, specific subpopulations of living neurons usually cannot be identified once the tissue has been dissociated and plated in culture. Recently, several groups have utilized retrogradely transported fluorescent markers to prelabel neurons in vivo prior to dissociation. This method has made it possible to identify spinal motor neurons (Calof and Reichardt, 1984; Eagleson and Bennett, 1983; Okun, 1981; Role et al., 1985) and retinal ganglion cells (Armson and Bennett, 1983; Leifer et al., 1984; Sarthy et al., 1983) in vitro.

Work from several laboratories (Dichter, 1978; Romijn et al., 1982; Swaiman et al., 1982; Thomas, 1985; Yavin and Yavin, 1977) has shown that neurons dissociated from the whole cerebral cortex of embryonic rodents survive in culture and express a variety of differentiated properties, including the formation of excitatory and inhibitory synaptic connections (Dichter, 1978). In the present study, we have developed dissociation and culture procedures that allow for the long-term survival of neurons from the visual cortex of postnatal Long Evans rats. Retrograde transport of fluorescent latex microspheres (Katz et al., 1984) has been used to prelabel neurons in layer $\mathrm{V}$ that project to the superior colliculus. As an initial step toward characterizing synaptic transmission between cortical neurons, we have used intracellular recording techniques to evaluate the response properties of labeled layer $\mathrm{V}$ neurons to excitatory amino acid agonists and antagonists. Preliminary reports of this work have been published (Huettner and Baughman, 1984, 1985).

\section{Materials and Methods}

\section{Tissue culture}

Long Evans rat pups (Charles River Breeding Labs), aged 1-15 d, were killed by cervical dislocation. Rectangular blocks of tissue, $2 \times 3 \mathrm{~mm}$, comprising area 17 (Krieg, 1946; Miller and Vogt, 1984) were removed from the occipital cortex of both hemispheres, placed in Earle's balanced salt solution (BSS) at $37^{\circ} \mathrm{C}$, and cut into $500 \mu \mathrm{m}$ slices with a scalpel. Slices of visual cortex from a single pup were incubated at $37^{\circ} \mathrm{C}$ with gentle stirring in $10 \mathrm{ml}$ of enzyme solution (Bader et al., 1978; Lam, 1972; Townes-Anderson et al., 1985) equilibrated with $95 \% \mathrm{O}_{2} / 5 \% \mathrm{CO}_{2}$. The enzyme solution contained $\mathrm{NaCl}, 116 \mathrm{~mm} ; \mathrm{KCl}, 5.4 \mathrm{~mm} ; \mathrm{NaHCO}_{3}$, $26 \mathrm{~mm} ; \mathrm{NaH}_{2} \mathrm{PO}_{4}, 1 \mathrm{~mm} ; \mathrm{CaCl}_{2}, 1.5 \mathrm{~mm} ; \mathrm{MgSO}_{4}, 1 \mathrm{~mm}$; EDTA, 0.5 $\mathrm{mm}$; glucose, $25 \mathrm{~mm}$; cysteine, $1 \mathrm{~mm}$; and papain (Cooper Biomedical, Malvern, PA), 200 units. After $1.5 \mathrm{hr}$, the slices were rinsed briefly with Earle's BSS containing BSA, $1 \mathrm{mg} / \mathrm{ml}$, and ovomucoid, $1 \mathrm{mg} / \mathrm{ml}$ (Sigma). The slices were gently triturated with a fire-polished Pasteur pipet in 2$3 \mathrm{ml}$ of this solution. Freshly dissociated cells that excluded the dye Erythrosin B (Phillips, 1973) were considered to be viable. Dissociated cells were harvested by low-speed centrifugation $(10 \mathrm{~min}, 70 \times \mathrm{g})$ through $5 \mathrm{ml}$ of Earle's BSS containing BSA $(10 \mathrm{mg} / \mathrm{ml})$ and ovomucoid $(10$ $\mathrm{mg} / \mathrm{ml}$ ). Cells were resuspended in growth medium and plated in modified petri dishes (Bray, 1970). Typically, cells from a single rat pup were used to prepare 40-50 culture dishes. Optimal viability and morphological preservation of the dissociated cells were obtained using the enzyme papain. In preliminary experiments, other enzymes, including trypsin, collagenase, dispase, hyaluronidase, and neuraminidase were evaluated and found to be clearly inferior to papain for dissociation of postnatal tissue.

The growth medium consisted of Eagle's MEM (Gibco, Grand Island, $\mathrm{NY}$ ) containing $0.5 \mathrm{~mm}$ glutamine, $20 \mathrm{~mm}$ glucose, and either gentamycin (50 $\mu \mathrm{g} / \mathrm{ml}$; Schering, Kenilworth, NJ) or penicillin (100 Units/ $\mathrm{ml})$ and streptomycin $(0.1 \mathrm{mg} / \mathrm{ml}$, Gibco). The medium was supplemented with $5 \%$ adult rat serum, which was prepared as described by Mains and Patterson (1973) and stored at $-80^{\circ} \mathrm{C}$. Cells were plated onto glass coverslips coated with a layer of dried rat tail collagen (Bornstein, 1958). The cell density at plating was approximately 100-200 cells/ $\mathrm{mm}^{2}$. Proliferation of non-neuronal cells was inhibited several days after plating by the addition of $10 \mu \mathrm{M} 1-\gamma$-D-arabinofuranosyl cytosine (ARAC) to the growth medium for $24-48 \mathrm{hr}$. In some experiments, freshly dissociated cells were plated onto a confluent layer of astrocytes. The astrocyte layers were obtained from cultures of newborn rat occipital cortex prepared as described above. Neurons in these cultures were killed by a single feeding with ice-cold growth medium. Freshly dissociated neurons plated onto a preexisting layer of astrocytes developed neurites much more rapidly than did cells plated onto collagen. In addition, the survival of neurons obtained from rat pups 9-15 d of age was enhanced by plating onto astrocytes. Cultures were maintained in a humid atmosphere of $95 \%$ air and $5 \% \mathrm{CO}_{2}$ at $37^{\circ} \mathrm{C}$. The cultures were fed every $4-5 \mathrm{~d}$ with $1 \mathrm{ml}$ of warm medium. We attempted to quantitate 


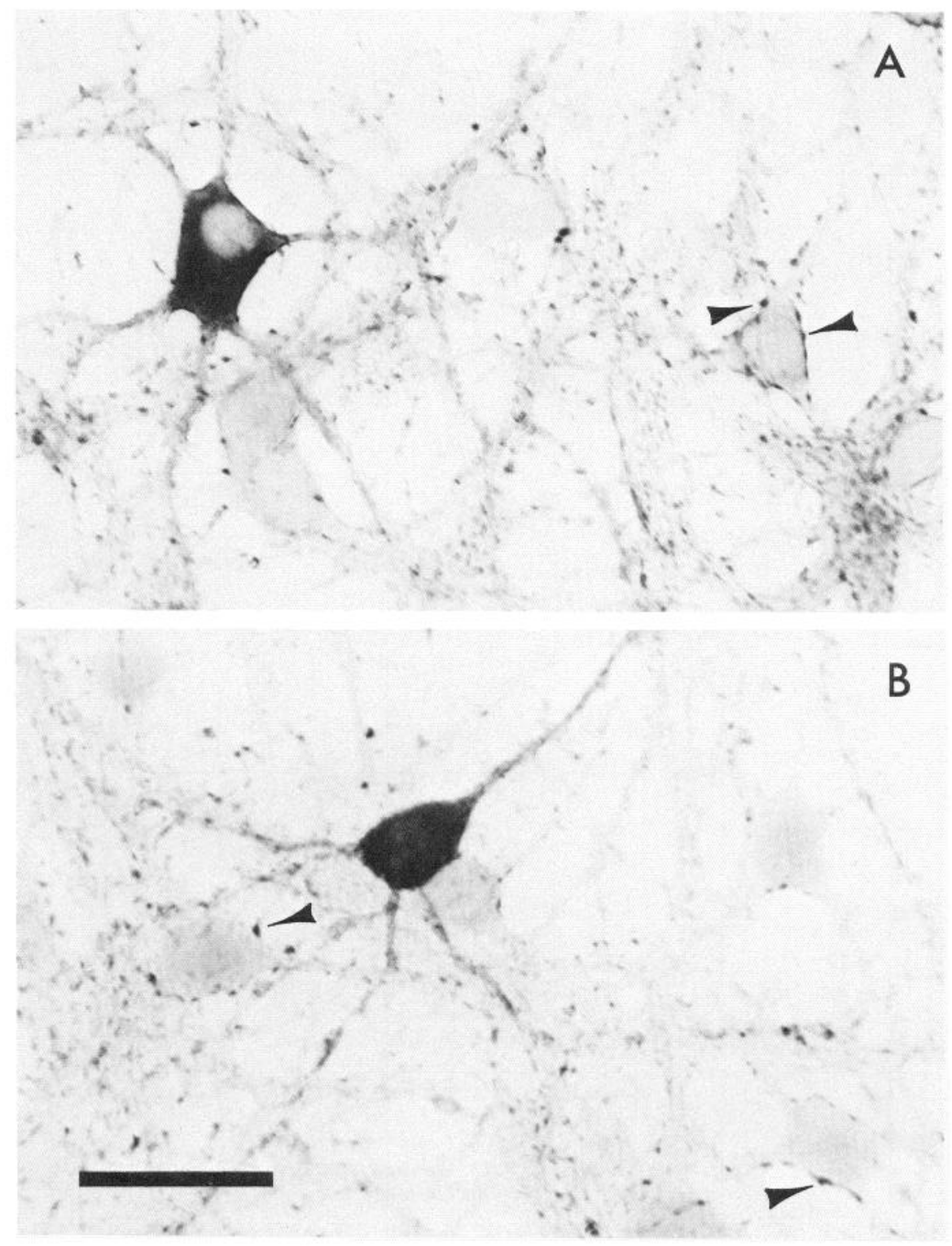

Figure 4. Immunohistochemical localization of glutamic acid decarboxylase-like immunoreactivity in normal $(A)$ and colchicine-treated $(B)$ cultures. Cultures were prepared from a 7-d-old animal and fixed after $20 \mathrm{~d}$ in vitro. Some GAD-positive varicosities (arrowheads) are closely associated with the somas of unstained neurons. Bar, $30 \mu \mathrm{m}$.

cell survival by counting neurons at weekly intervals; however, cultures that were counted deteriorated much more rapidly than sister cultures that were not counted. To provide an estimate of neuronal survival, cell counts of cultures fixed after 3-4 weeks in vitro were compared to the initial plating density of $100-200$ cells $/ \mathrm{mm}^{2}$. Based on counts of 35 cultures, we estimate that $50-70 \%$ of the neurons initially plated remained viable after 3-4 weeks in vitro. Using the methods described above, we have prepared viable dissociated neurons from adult rats, 35 months old. However, neurons from animals older than $15 \mathrm{~d}$ of age have not survived in long-term cultures.

\section{Immunohistochemistry}

Cultures used for immunocytochemistry were washed 3 times with warm MEM containing $20 \mathrm{~mm}$ glucose and immersed in fixative. To examine neurofilament-like (NF-IR) and glial fibrillary acidic protein-like (GFAPIR) immunoreactivities, cultures were fixed for $20 \mathrm{~min}$ in $0.1 \mathrm{M}$ sodium

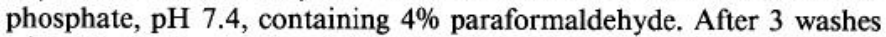
with Tris-buffered saline (TBS), $\mathrm{pH} 7.4$, cultures were incubated for 5 min in TBS containing $0.2 \%$ Triton X-100 (TX-100). Cultures were then washed 3 times with TBS and incubated for $15 \mathrm{~min}$ in TBS with $3 \%$ normal goat serum. Cultures were incubated for $1 \mathrm{hr}$ in rabbit antiserum to $\alpha$-melanocyte-stimulating hormone (Immunonuclear, Stillwater, MN) in TBS containing 3\% normal goat serum, $2 \%$ BSA, and $0.1 \% \mathrm{TX}-100$. This antiserum has been shown to cross-react with the $150 \mathrm{kDa}$ subunit of neurofilaments (Dräger et al., 1983). The cultures were rinsed 3 times with TBS and incubated for $1 \mathrm{hr}$ with fluorescein isothiocyanate-conjugated goat anti-rabbit immunoglobulin (Cappel, Cochranville, PA) diluted 1:40 in TBS containing 3\% normal goat serum and $2 \%$ BSA. After 3 washes with TBS, cultures were incubated for 1 $\mathrm{hr}$ with rat antibodies to GFAP (Bignami et al., 1972) diluted 1:10 in TBS containing $2 \%$ BSA, $3 \%$ normal rabbit serum, and $0.1 \%$ TX- 100 . Cultures were washed with TBS and incubated for $1 \mathrm{hr}$ with rhodamine isothiocyanate-conjugated rabbit anti-rat immunoglobulin (Cappel), diluted 1:40 in TBS containing 2\% BSA and 3\% normal rabbit serum. Cultures were washed again and examined with a Zeiss microscope equipped for phase microscopy and epifluorescent illumination.

To examine glutamic acid decarboxylase-like (GAD-IR) and vasoactive intestinal polypeptide-like(VIP-IR) immunoreactivities, cultures

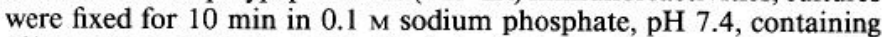
$4 \%$ paraformaldehyde and $0.1 \%$ glutaraldehyde. This was followed by a second fixation for $10 \mathrm{~min}$ in $0.1 \mathrm{~m}$ sodium borate, $\mathrm{pH} 9.75$, containing $4 \%$ paraformaldehyde. To stain for choline acetyltransferase-like (ChATIR) immunoreactivity, cultures were fixed for $20 \mathrm{~min}$ with $0.1 \mathrm{M}$ sodium phosphate containing $4 \%$ paraformaldehyde and $15 \%$ picric acid. Cultures were washed 3 times with TBS and incubated 18-24 hr with primary antiserum. Sheep anti-GAD (Oertel et al., 1981) and mouse anti-ChAT (Eckenstein and Thoenen, 1982) were diluted 1:1000 with 


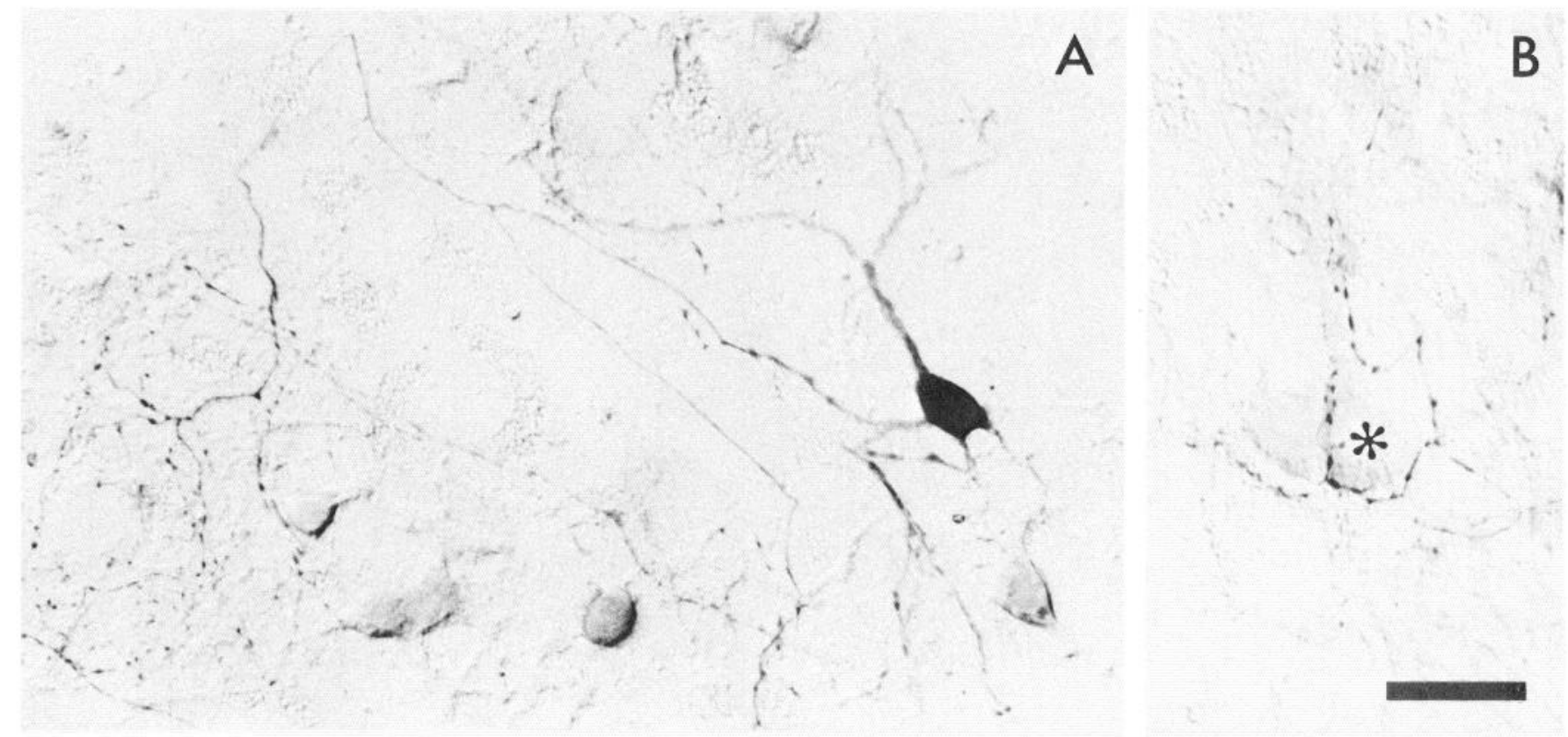

Figure 5. Immunohistochemical localization of vasoactive intestinal polypeptide-like immunoreactivity. Cultures were prepared from an 8-d-old animal and fixed after $24 \mathrm{~d}$ in vitro. $A$, Cell body and processes of a VIP-positive neuron. $B$, Higher magnification photomicrograph of a VIPpositive fiber with varicosities encircling an unstained cell soma (asterisk). Bar: $A, 30 \mu \mathrm{m} ; B, 20 \mu \mathrm{m}$.
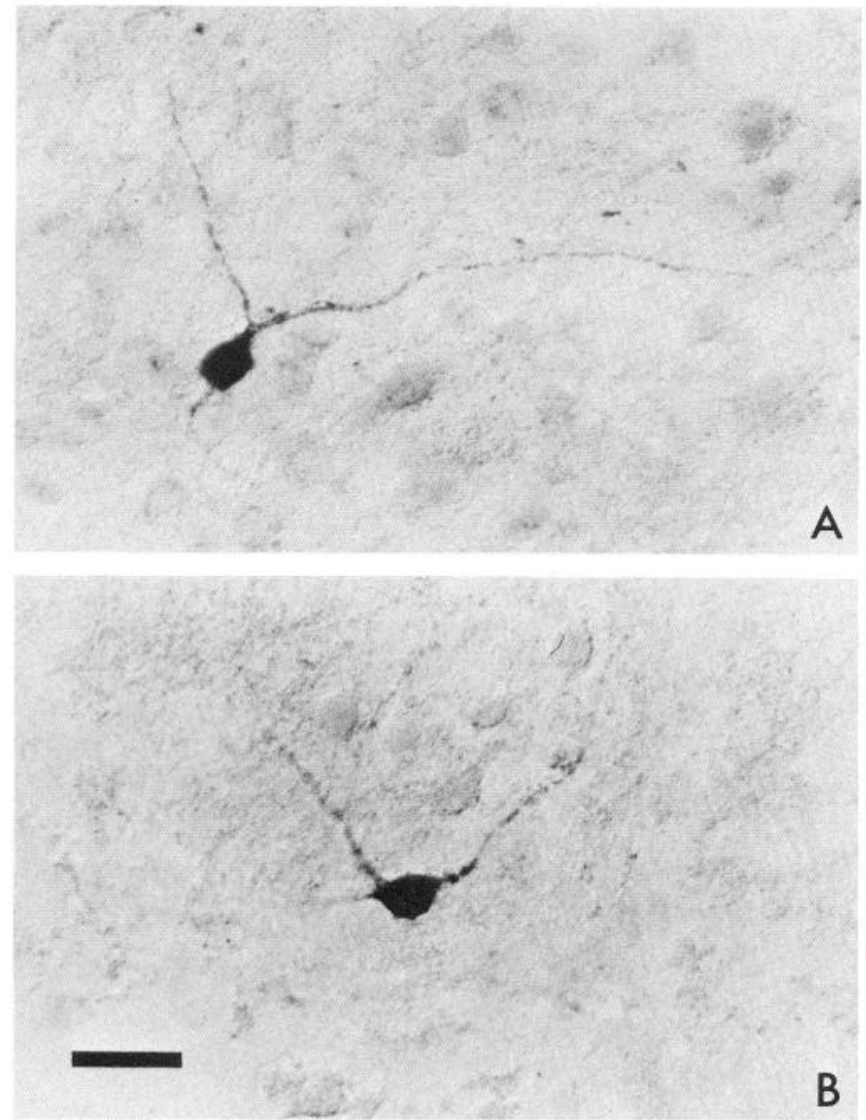

Figure 6. Immunohistochemical localization of choline acetyltransferase-like immunoreactivity. Cultures were prepared from a 7-d-old animal and fixed after $20 \mathrm{~d}$ in vitro. $A$ and $B$, Two ChAT-positive neurons and many unstained neurons are shown. Bar, $30 \mu \mathrm{m}$.
TBS containing $2 \% \mathrm{BSA}, 0.1 \%$ TX-100, and $20 \%$ normal rabbit serum. Rabbit anti-VIP (Eckenstein and Baughman, 1984) was used at a dilution of $1: 1000$ in TBS containing $2 \%$ BSA, $0.1 \%$ TX-100, and $20 \%$ normal goat serum. Following the primary incubation, cultures were rinsed 3 times and incubated for $1 \mathrm{hr}$ with secondary antiserum diluted $1: 40$ in TBS containing $2 \%$ BSA and $3 \%$ normal rat serum. Goat anti-rabbit immunoglobulin, rabbit anti-mouse immunoglobulin, and a rabbit anti-goat immunoglobulin that cross-reacts with sheep immunoglobulin were used as the secondary antisera (Sternberger-Meyer, Jarrettsville, MD). Cultures were then rinsed 3 times with TBS and incubated for $1 \mathrm{hr}$ with goat, mouse, or rabbit peroxidase-anti-peroxidase (PAP, Sternberger-Meyer) diluted 1:40 in TBS containing 2\% BSA and $3 \%$ normal rat serum. The cultures were rinsed again with TBS and incubated for another hour with secondary antiserum, then rinsed and incubated with PAP for an hour. After a final 3 rinses with PBS, the cultures were incubated with $0.1 \mathrm{M}$ sodium phosphate containing $0.03 \%$ $\mathrm{H}_{2} \mathrm{O}_{2}$ and $0.1 \%$ 3-3'-diaminobenzidine tetrahydrochloride (DAB). The reaction was terminated by washing with PBS. Cultures were then treated briefly with PBS containing $0.1 \%$ osmium tetroxide, dehydrated with ethanol, and mounted on slides.

\section{Retrograde labeling}

Neurons in layer $\mathrm{V}$ of the visual cortex that project to the superior colliculus were labeled in vivo by retrograde transport of fluorescent latex microspheres (Katz et al., 1984; microspheres can be obtained from Tracer Technology, P.O.B. 7, Bardonia, NY 10954). Rat pups were anesthetized with halothane and their heads were secured with plasticine. A small hole was drilled in the skull directly behind the lambdoid suture, and microspheres suspended in saline were deposited bilaterally into the superior colliculi by pressure ejection from a blunt micropipet mounted on a micromanipulator. The mean diameter of the microspheres in the injected suspension was approximately $20 \mathrm{~nm}$ (Katz et al., 1984; Andreas Burkhalter, personal communication). After 36$48 \mathrm{hr}$ survival time, animals were used to prepare cultures or were

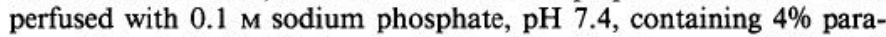
formaldehyde for histologic examination. Fixed brains were equilibrated with $30 \%$ sucrose and sectioned on a cryostat. Mounted sections were counterstained with 4',6-diamidino-2-phenylindole (Sigma) and airdried. The slides were immersed for $30 \mathrm{sec}$ in $100 \%$ alcohol and $30 \mathrm{sec}$ in xylene before coverslipping with krystalon (Harleco, Gibbstown, NJ). 

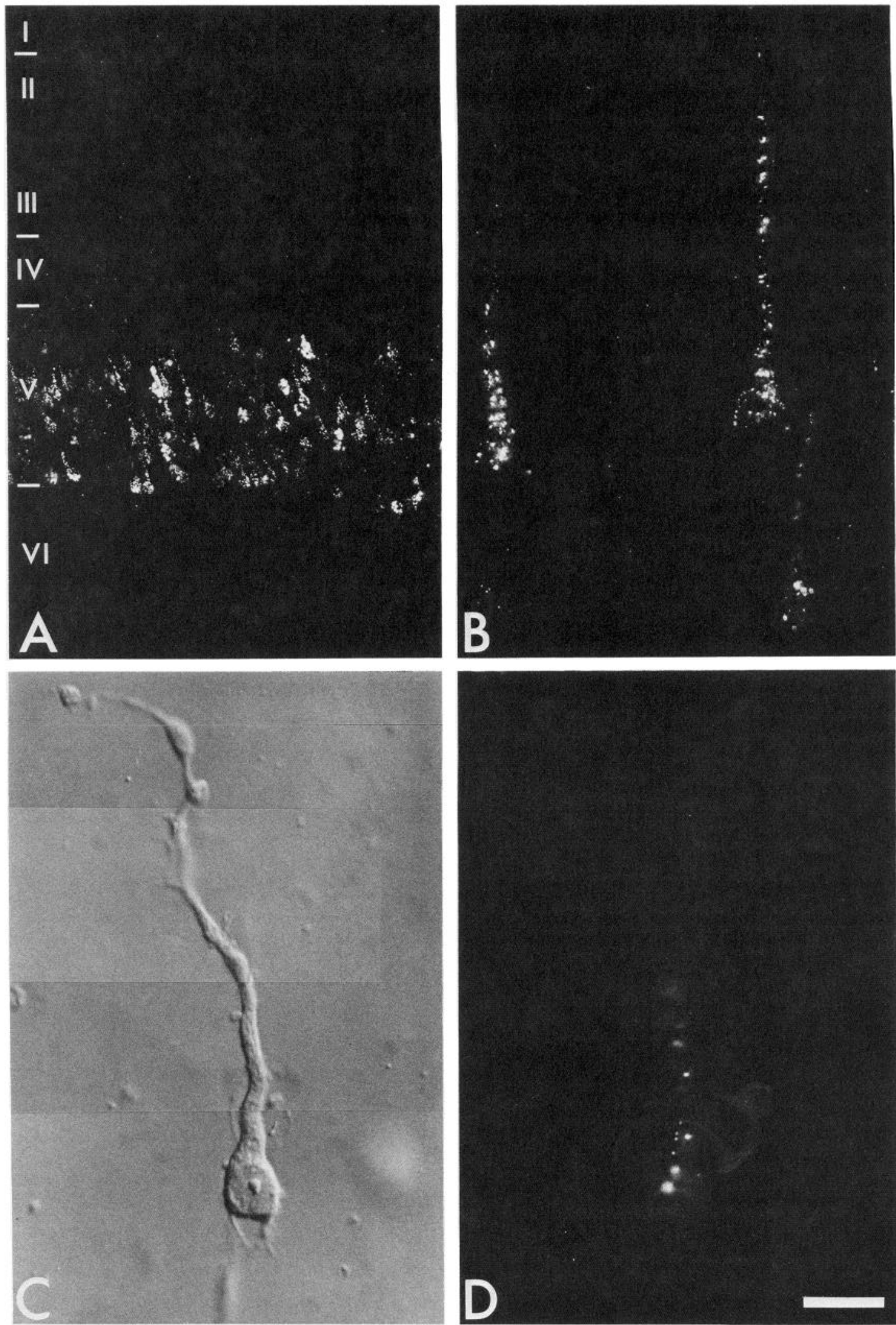

Figure 7. Fluorescence photomicrographs of labeled cells in layer $\mathrm{V}$ of the visual cortex after an injection of fluorescent latex microspheres into the superior colliculus. $A$, Roman numerals indicate the layers of the cortex. $B$, Higher magnification photomicrograph of labeled neurons within layer V. Fluorescent particles are present in the cell bodies and apical dendrites of 3 pyramidal neurons. Also shown are Nomarski (C) and fluroescence $(D)$ photomicrographs of a freshly dissociated neuron obtained from an 8-d-old animal that received an injection of fluorescent microspheres in the superior colliculus on postnatal day 5 . The cell contains numerous fluorescent particles and is thus identified as a corticocollicular neuron. Bar: $A, 75 \mu \mathrm{m} ; B-D, 30 \mu \mathrm{m}$. 

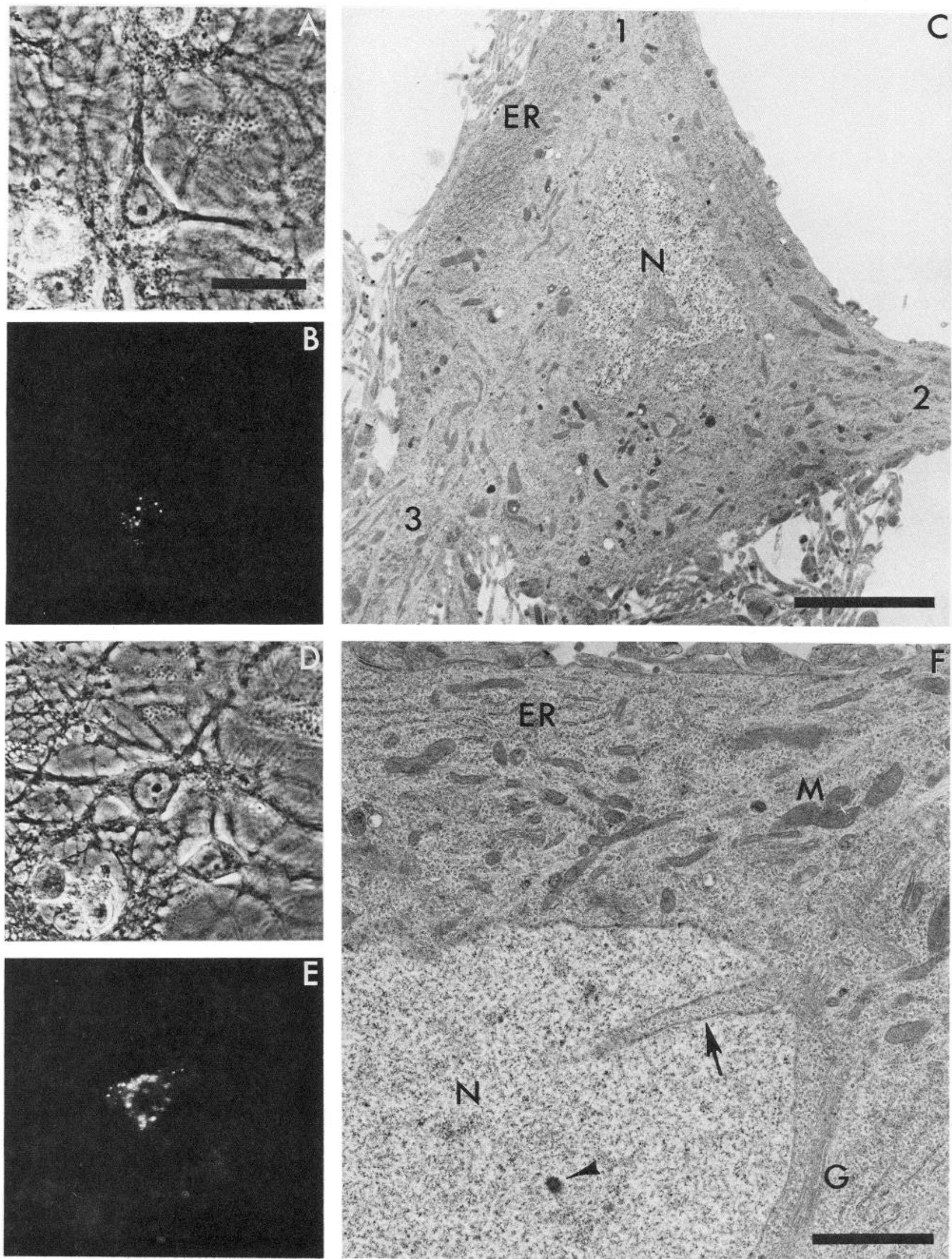

Figure 8. Fine structure of corticocollicular neurons in culture for $15 \mathrm{~d}$. $A$ and $D$, Phase-contrast photomicrographs of cortical neurons in cultures prepared from an 8-d-old animal. $B$ and $E$, Fluorescence photomicrographs of the same fields as in $A$ and $D$, respectively. One neuron in each field is brightly labeled. $C$, Low-power electron micrograph of the labeled neuron in $A$ and $B$. The nucleus $(N)$ has a folded envelope that forms a complete partition in this plane of section. Well-ordered stacks of granular endoplasmic reticulum $(E R)$ lie adjacent to the plasmalemma. The 

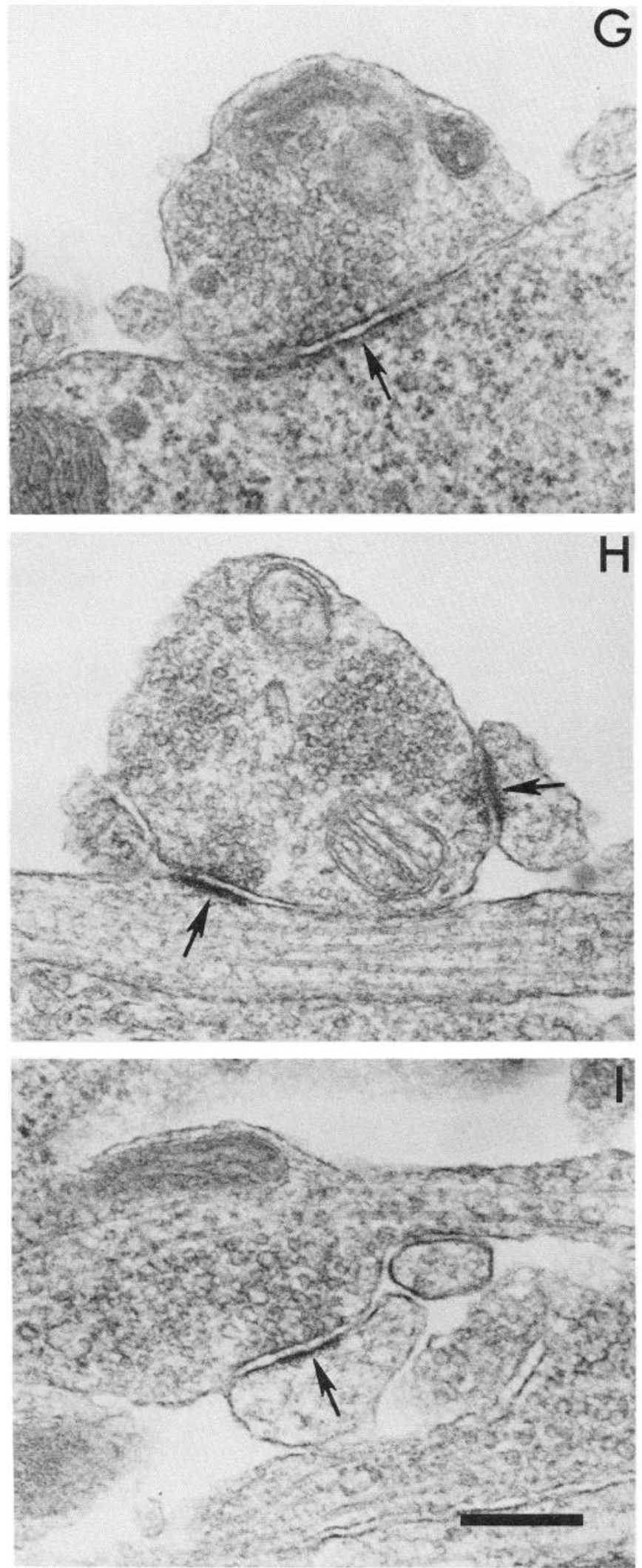

perikaryon gives rise to 3 dendritic processes $(1-3), 2$ of which $(1$ and $2)$ are visible in the phase-contrast micrograph of this cell $(A) . F$, Electron micrograph of the labeled cell in $D$ and $E$. The nucleus $(N)$ contains relatively homogeneous karyoplasm and has a smooth outline except for the sharp cleft indicated by the arrow. A small portion of the nu-
Fluorescent microspheres in cultured neurons and in tissue sections were visualized with a rhodamine filter set (exciter BP $510-560 \mathrm{~nm}$, beam splitter FT $580 \mathrm{~nm}$, barrier LP $590 \mathrm{~nm}$ ) on a Zeiss microscope equipped for epifluorescent illumination. For most experiments, animals were injected on postnatal day 5 or 6 and sacrificed on day 7 or 8 .

\section{Electron microscopy}

Cultures grown on aclar (Allied Chemical Co., Morristown, NJ) coverslips were fixed for $1-2 \mathrm{hr}$ with $0.12 \mathrm{M}$ sodium phosphate, $\mathrm{pH} 7.4$, containing $3 \%$ glutaraldehyde. Neurons containing fluorescent latex microspheres were photographed, and their locations on the coverslips were marked. The cells were then postfixed with $2 \%$ osmium tetroxide for $30 \mathrm{~min}$, stained en bloc with $1 \%$ uranyl acetate for $2-3 \mathrm{hr}$, dehydrated with ethanol, and embedded in Epon (Landis, 1976). Retrogradely labeled neurons were relocated and mounted for thin sectioning. Sections were stained with lead citrate and examined under the EM.

\section{Electrophysiology}

Recording procedures were similar to those described by O'Lague et al. (1978). The culture dish was mounted on the stage of an inverted microscope with phase-contrast optics. A heated brass collar held the dish rigidly in place and maintained the temperature at $30^{\circ} \mathrm{C}$. A stainlesssteel annulus was inserted into the culture dish to restrict the fluid volume to approximately $0.2 \mathrm{ml}$. The culture was continuously perfused at a rate of $1 \mathrm{ml} / \mathrm{min}$ with medium containing $10 \% \mathrm{MEM}$ ( $\mathrm{vol} / \mathrm{vol}), 1 \%$ heat-inactivated horse serum (Gibco), and in final concentrations (mM): $\mathrm{NaCl}, 135 ; \mathrm{KCl}, 5.3 ; \mathrm{NaHCO}_{3}, 4.2 ; \mathrm{NaH}_{2} \mathrm{PO}_{4}, 0.8 ; \mathrm{MgSO}_{4}, 1 ; \mathrm{CaCl}_{2}$, 3; glucose, 30; HEPES, 5 (pH 7.4). A polyethylene tube filled with $2.5 \%$ agar in saline served as a salt bridge from the culture well to the reference electrode $(\mathrm{Ag}: \mathrm{AgCl})$. Various media containing drugs could be selected for perfusion by means of a multichannel distribution valve.

Microelectrodes were pulled from thin-walled "omega dot" tubing (Glass Company of America, Bargaintown, NJ) and filled with $0.2 \mathrm{M}$ potassium acetate containing $10 \mathrm{~mm}$ HEPES, pH 7.2, or occasionally $0.2 \mathrm{~m}$ potassium methylsulfate, $10 \mathrm{~mm}$ HEPES, $\mathrm{pH} 7.2$ (resistance in perfusion medium $70-100 \mathrm{M} \Omega$ ). In some experiments, electrodes were filled with $0.2 \mathrm{M}$ lithium acetate containing $10 \mathrm{~mm}$ HEPES, $\mathrm{pH} 7.2$, and $0.4 \%$ Lucifer Yellow (Stewart, 1981). A bridge circuit was used to pass current while recording.

The sensitivity of neurons to excitatory amino acid agonists was tested with a pressure-ejection system (Choi and Fischbach, 1981). A blunt micropipet (10-30 $\mu \mathrm{m}$ tip diameter) containing an agonist dissolved in recording medium was positioned $100-200 \mu \mathrm{m}$ from the soma. Drug solution was ejected from the pipet with $1-5 \mathrm{sec}$ pulses of pressure (2$5 \mathrm{psi})$. The inert dye Fast green was added to the drug solution $(0.1 \%)$ to allow for visualization of the ejected material. The area affected by each puff of drug solution was approximately $200-300 \mu \mathrm{m}$ in diameter. In some experiments, excitatory amino acid antagonists were added to the bath and to the agonist pipet.

\section{Results}

Mild enzymatic and mechanical dissociation of cortical tissue from early postnatal Long Evans rats yielded a high proportion of viable cells (Fig. 1A). Approximately $90 \%$ of the cells obtained from rats $1-15 \mathrm{~d}$ old excluded the dye Erythrosin B. The total number of dissociated cells obtained from the 2 visual cortices

cleolus can be seen in this section (arrowhead). The perikaryal cytoplasm contains a variety of organelles, including the Golgi apparatus $(G)$, mitochondria $(M)$, cisternae of granular endoplasmic reticulum $(E R)$, and numerous free ribosomes. $G-I$, Examples of synaptic contacts formed on $(G)$ or near ( $H$ and $I$ ) the cell in $A-C$. These electron micrographs were taken from other sections of this cell than the one shown in $C$. In each case, the arrows lie within the postsynaptic element and indicate the synaptic junction. The presynaptic axon terminals contain mitochondria and numerous synaptic vesicles. Bar: $A, B, D$, and $E, 30 \mu \mathrm{m}$; $C, 5 \mu \mathrm{m} ; D, 2 \mu \mathrm{m} ; G-I, 300 \mathrm{~nm}$. 

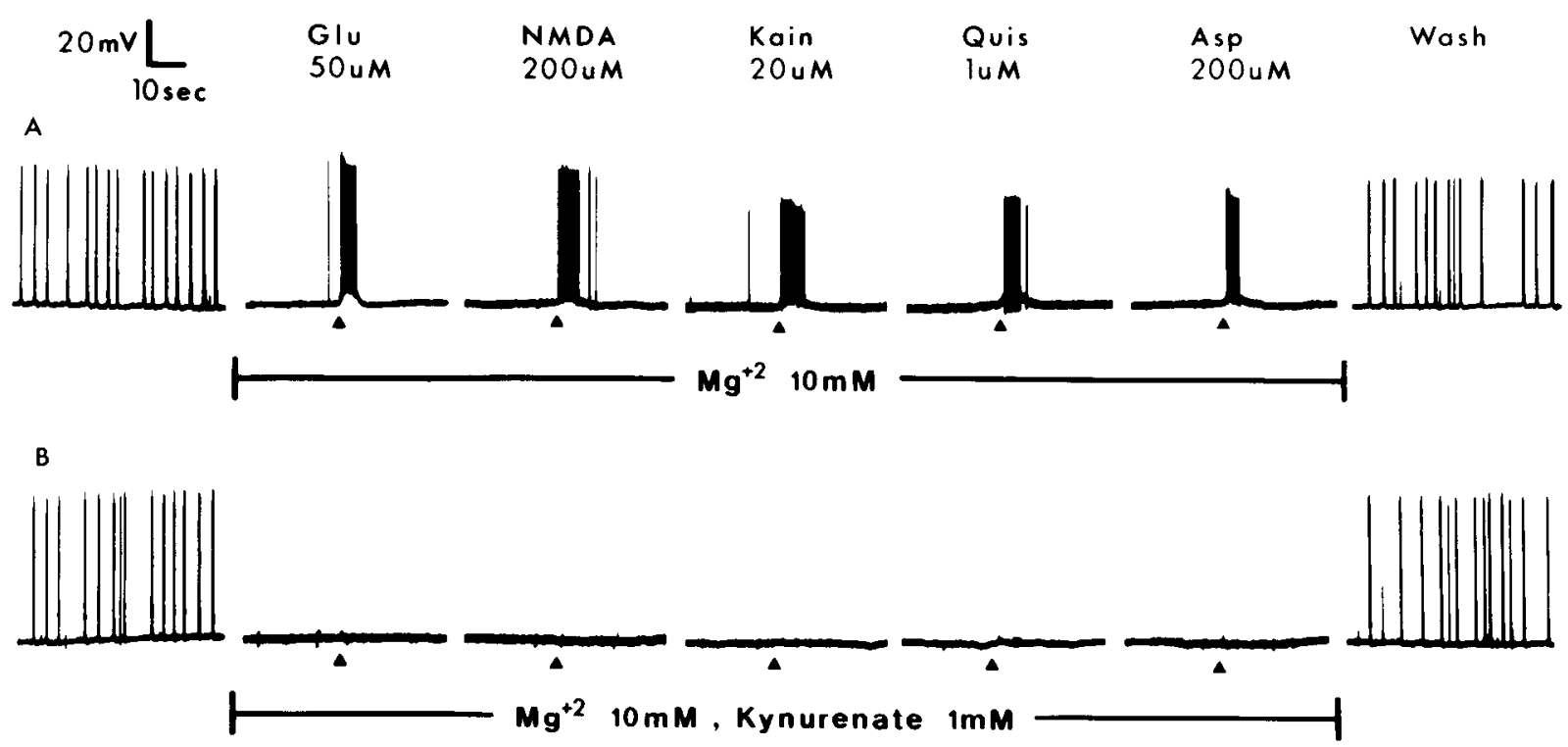

Figure 9. Effect of high $\mathrm{Mg}^{+2}(A)$ and high $\mathrm{Mg}^{+2}$ plus $1 \mathrm{~mm}$ kynurenate $(B)$ on the responses of 2 corticocollicular neurons to excitatory amino acids. $A$, First trace shows spontaneous activity of the cell at the beginning of the recording. Superfusion of the culture with $10 \mathrm{~mm} \mathrm{MgCl}_{2}$ eliminated the spontaneous activity. Glutamate, $N$-methyl-D-aspartate, kainate, quisqualate, and aspartate were applied (at the triangles) by pressure ejection ( $1 \mathrm{sec}$ pulses) from a pipet positioned near the cell. Spontaneous activity returned in normal recording medium $\left(3 \mathrm{mM} \mathrm{Ca}^{+2} / 1 \mathrm{~mm} \mathrm{Mg}^{+2}\right)$. $B$, Recordings from another corticocollicular neuron in the same culture. The culture was superfused with $10 \mathrm{mM} \mathrm{MgCl}_{2}$ plus $1 \mathrm{~mm}$ kynurenate during the period indicated by the $b a r$. Agonists were applied as in $A$. In both $A$ and $B$, the culture was prepared from a 7-d-old animal and the recordings were obtained after $30 \mathrm{~d}$ in vitro.

was roughly 3-6 million (Fig. $1 B$ ). Many of the dissociated cells retained long processes and had recognizable neuronal morphology. A typical freshly dissociated cell is shown in Figure $2 A$. This cell, which was obtained from an 8-d-old rat, resembled a cortical pyramidal neuron with a prominent apical dendrite (oriented up) and several smaller basal dendrites still intact.

Cortical cells from rat pups $1-8 \mathrm{~d}$ old rapidly adhered to collagen-coated glass coverslips and began to extend processes within 3-6 hr (Fig. 2B). Neurons in culture had phase-bright cell bodies, and developed long processes that formed a complicated network during the first week in vitro. Non-neuronal cells multiplied in culture to form a confluent background layer of flat, phase-dark cells. Treatment of confluent cultures with $10 \mu \mathrm{M}$ ARA-C for $24-48 \mathrm{hr}$ halted the proliferation of nonneuronal cells. Figure $2 D$ shows 5 phase-bright neurons obtained from a 3-d-old animal growing on a confluent layer of nonneuronal cells. A neuron obtained from a 15-d-old animal is shown in Figure $2 C$ after $19 \mathrm{~d}$ in culture.

Immunofluorescent staining for GFAP (Bignami et al., 1972) and for the $150 \mathrm{kDa}$ subunit of neurofilaments (Anderton et al., 1980; Liem et al., 1978; Schlaepfer and Freeman, 1978) revealed that nearly all of the process-bearing cells with neuronal morphology possessed NF-IR (Fig. 3B). Almost all of the flat background cells exhibited GFAP-IR (Fig. 3C) and were thus identified as astrocytes (Antanitus et al., 1975; Raff et al., 1979). Background cells did not possess NF-IR, and none of the cells with neuronal morphology exhibited GFAP-IR. Neurons routinely survived in culture for 3-4 weeks and in many cases for 8-10 weeks or more.

\section{Immunohistochemistry}

GAD-IR was observed in the processes and cell bodies of a subpopulation of cortical neurons in culture. Figure $4 A$ shows a GAD-positive cell body with multipolar morphology; in this, as in most cells, the $\mathrm{DAB}$ reaction product was excluded from the nucleus. GAD-positive processes possessed many varicosities and were frequently observed in close contact with neuronal somata (Fig. 4, arrows). In some experiments, cultures were incubated with colchicine (100-500 $\mathrm{nM}$ ) for $24-36 \mathrm{hr}$ prior to fixation. This colchicine treatment enhanced the staining of cell bodies and proximal dendrites and reduced, but did not eliminate, staining of processes and varicosities (Fig. 4B). Cell counts of colchicine-treated cultures revealed that $22 \pm 2 \%(n=11)$ of the neurons exhibited GAD-IR.

Antiserum to the neuropeptide VIP stained the cell bodies and processes of a small percentage of cortical neurons (Fig. 5). In cultures treated with colchicine, approximatcly $2.4 \pm 0.2 \%$ $(n=8)$ of all neurons possessed VIP-IR. The processes of individual VIP-positive neurons could be followed for 100-300 $\mu \mathrm{m}$. Frequent swellings or varicosities were observed along the length of most stained processes (Fig. $5 B$ ). Preadsorption of the antiserum with synthetic VIP completely eliminated the staining. Antiserum to the enzyme choline acetyltransferase stained a subpopulation of cortical neurons comprising $2.3 \pm 0.3 \%(n=$ 8) of all cells (Fig. 6). Optimal staining for ChAT-IR was obtained using $4 \%$ paraformaldehyde and $15 \%$ picric acid as the fixative; however, this fixation yielded relatively poor morphological preservation of neuronal processes. Substitution of preimmune sheep, rabbit, or mouse serum for each of the primary antisera above resulted in no detectable staining. In some experiments, cultures stained for GAD-IR, VIP-IR, or ChATIR also contained neurons that had been labeled, prior to the dissociation, by retrograde transport of fluorescent microspheres from the superior colliculus (see below). Corticocollicular neurons in vivo do not exhibit immunoreactivity for GAD, ChAT, or VIP (Eckenstein and Baughman, 1984; Ribak, 1978). In culture, the retrogradely labeled neurons were never observed to stain with these 3 antisera.

\section{Retrograde labeling}

Bilateral injections of fluorescent latex microspheres into the superior colliculus produced bright labeling of neurons in layer $\mathrm{V}$ of the visual cortex (Fig. 7A), as well as in the retina and other parts of the CNS that are known to innervate the superior col- 

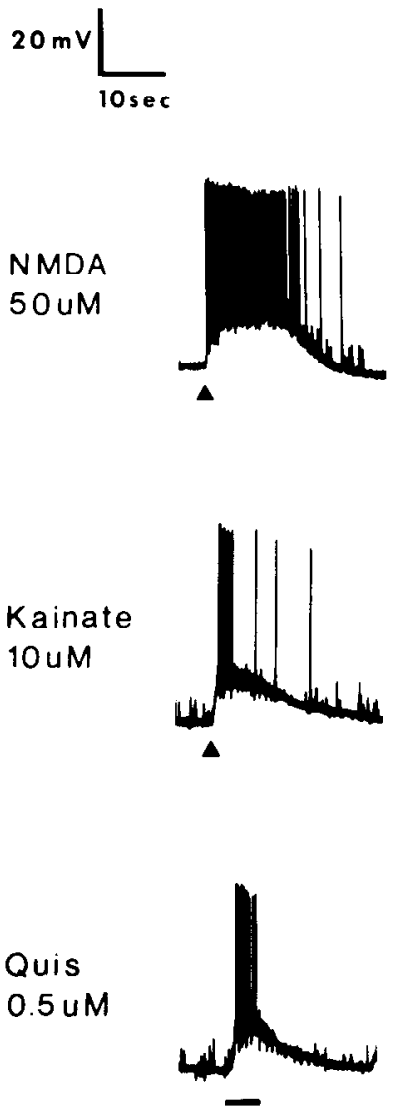
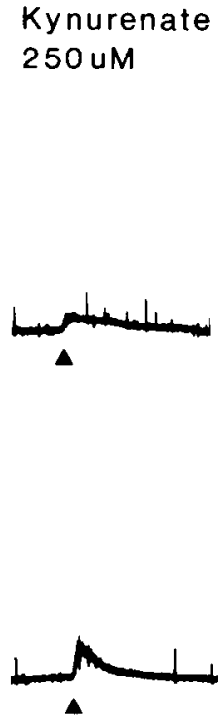

$250 u \mathrm{M}$
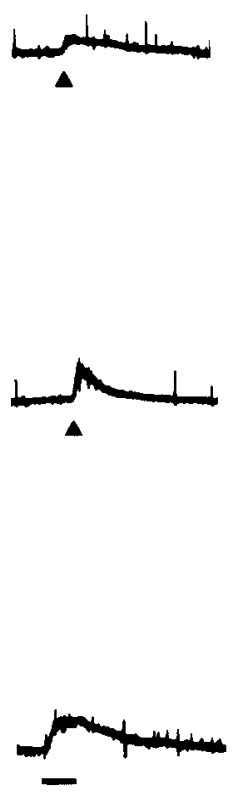

APV

$50 \mathrm{uM}$
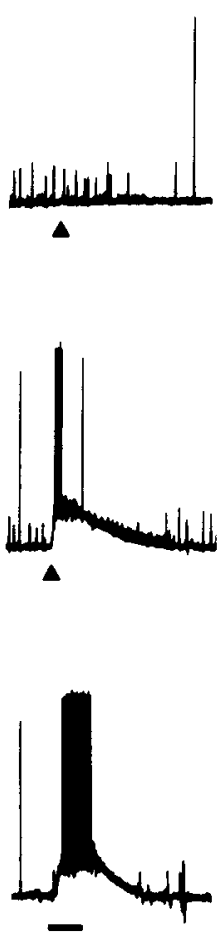

GDEE

$500 u M$
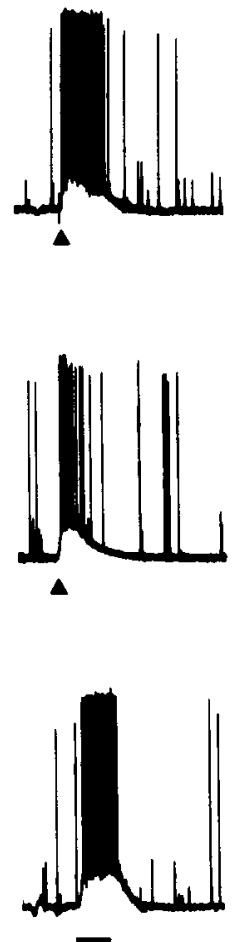

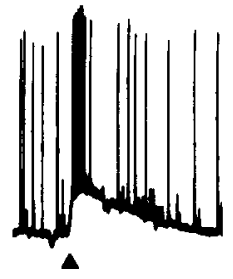

Wash
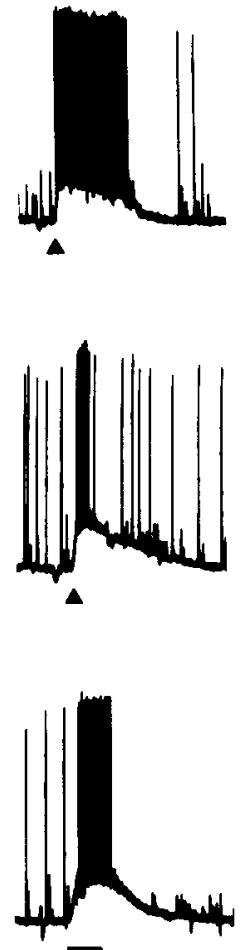

Figure 10. Effect of kynurenate, 2-amino-5-phosphonovalerate, and glutamic acid diethyl ester on the responses of a corticocollicular neuron to $N$-methyl-D-aspartate, kainate, and quisqualate. The cell was first exposed to brief applications of $50 \mu \mathrm{M}$ NMDA (1 sec), $10 \mu \mathrm{M}$ kainate (1 sec), and $0.5 \mu \mathrm{M}$ quisqualate $(3 \mathrm{sec})$ in normal recording medium. The agonist applications were repeated during superfusion of the culture with $250 \mu \mathrm{M}$ kynurenate, $50 \mu \mathrm{M} \mathrm{APV}$, and $500 \mu \mathrm{M}$ GDEE, and during a final wash with normal medium. The culture was prepared from a 7-d-old animal and the recording was obtained after $20 \mathrm{~d}$ in vitro.

liculus. Figure $7 B$ shows labeled pyramidal neurons within layer $\mathrm{V}$ at higher magnification. The labeled cells contained a profusion of highly fluorescent particles in their perikarya and proximal dendrites. Within layer V, approximately $30-40 \%$ of the neurons were labeled, while roughly $1-3 \%$ of all cells in the primary visual cortex as a whole were labeled. Retrogradely labcled ncurons were readily identified immediately after dissociation (Fig. 7, $C$ and $D$ ) and throughout the period of culture (Figs. 8, 14). Cell counts revealed that $1.6 \pm 0.1 \%(n=7)$ of the freshly dissociated cells contained fluorescent microspheres. After 2-4 weeks in culture, $1.5 \pm 0.1 \%(n=10)$ of all neurons in culture were labeled. Visualization of the microspheres (510$560 \mathrm{~nm}$ excitation wavelength) did not damage living cells, and because the microspheres do not bleach rapidly (Katz et al., 1984), labeled neurons could be examined repeatedly over a period of many weeks.

\section{Electron microscopy}

Retrogradely labeled neurons maintained in culture for $15 \mathrm{~d}$ exhibited many ultrastructural features characteristic of cortical pyramidal neurons in vivo. Figure 8 shows 2 cells that were identified in vitro as labeled corticocollicular neurons and were then processed for electron-microscopic examination. Each cell had a large nucleus containing homogeneous karyoplasm and a single nucleolus. In general, the outline of the nucleus formed a gentle curve with occasional moderate folds. In some cells, however, a sharp crease or cleft was observed on one side of the nucleus (Peters, 1985; Peters et al., 1976). Prominent Golgi bodies and plentiful mitochondria and polyribosomes were ob- served in the cytoplasm as well as abundant rough endoplasmic reticulum that was frequently arranged into well-organized stacks adjacent to the nucleus or the plasmalemma. Numerous multivesicular bodies were found throughout the cytoplasm, while granular lysosomes were less common. Usually, the neurons exhibited 3-6 large processes that arose as gradually tapering extensions of the perikaryal cytoplasm and resembled dendrites. Thinner neurites with a more abrupt origin from the perikaryon were observed occasionally; it was not possible, however, to determine whether these processes were axons or dendrites since they quickly became lost in the tangle of neurites surrounding cach ccll.

Synaptic contacts were observed on the cell bodies and proximal dendrites of all 11 neurons examined in the EM, and numerous synaptic profiles were found in the neuropil adjacent to each labeled cell. Figure $8 G$ shows a synapse on the cell body of the corticocollicular neuron shown in panels $A-C$. Two examples of synaptic profiles in the neuropil surrounding this cell are shown in Figure $8, H$ and $I$. In the present study we did not evaluate the number or distribution of synapses, nor did we attempt to classify the synaptic morphology. We were not able to localize the fluorescent microspheres at the ultrastructural level. Individual microspheres are approximately $20 \mathrm{~nm}$ in diameter, and it is known that they dissolve in the organic solvents used for infiltration and embedding of the cells (Katz et al., 1984). Multivesicular bodies, which represent a possible storage site for retrogradely transported microspheres, were found in all of the neurons examined, including many unlabeled cells that were adjacent to retrogradely labeled neurons. We could not 


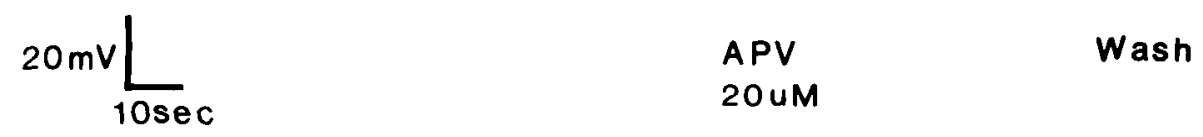

Figure 11. Effect of 2-amino-5phosphonovaleric acid on the responses of a cortical neuron to glutamate and $N$-methyl-D-aspartate. Traces on the left show response of the cell to $1 \mathrm{sec}$ applications of $20 \mu \mathrm{M}$ glutamate and $100 \mu \mathrm{M}$ NMDA in normal recording medium. The culture was then superfused with $20 \mu \mathrm{M}$ APV and 3 brief pulses $(1 \mathrm{sec})$ of glutamate and NMDA were applied (at the triangles). Traces on the right show rcsponses of the cell to glutamate and NMDA after washing out the APV with normal recording medium. The culture was prepared from a 7-d-old animal and the recording was obtained after $15 \mathrm{~d}$ in vitro.

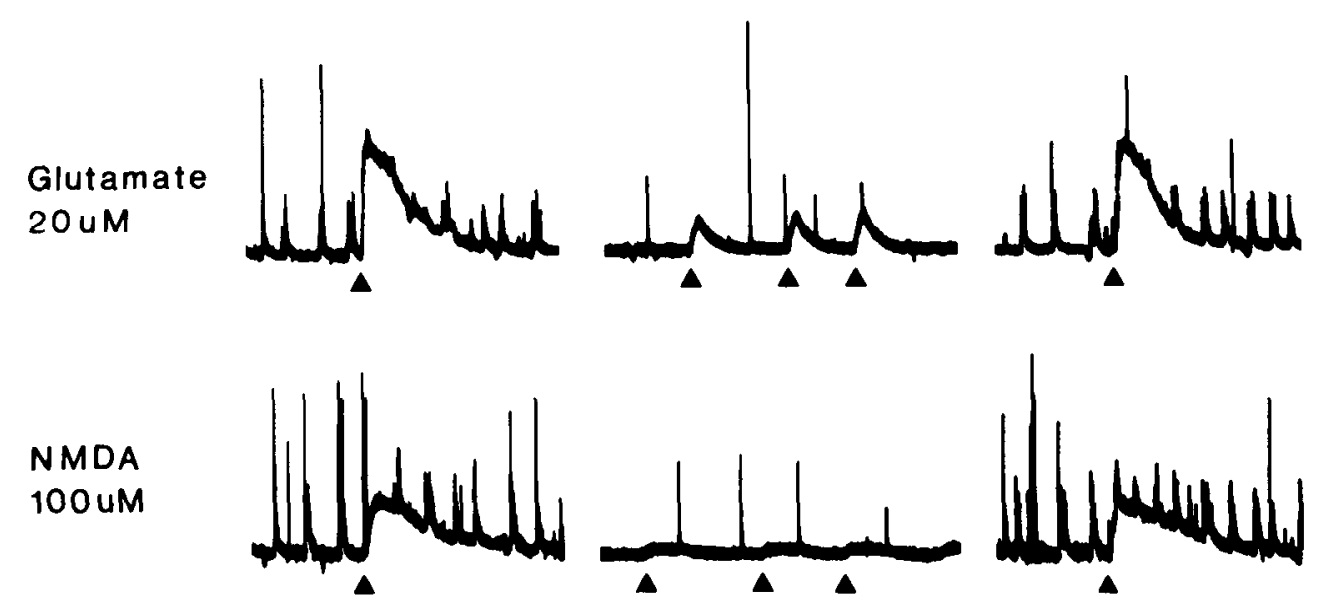

detect any difference in the appearance of these structures within the labeled and unlabeled neurons.

\section{Electrophysiology}

Intracellular recordings were obtained from 71 retrogradely labeled layer $\mathrm{V}$ neurons and from many unlabeled neurons as well. Cells from different platings displayed similar properties, and no significant variation was observed for neurons after 210 weeks in culture. Resting potentials ranged from -45 to -68 $\mathrm{mV}$, and stable impalements were maintained for $30 \mathrm{~min}$ to several hours. Brief depolarizing current pulses elicited one or more action potentials in all neurons studicd. In addition, virtually every neuron exhibited frequent spontaneous EPSPs and
IPSPs that were reversibly abolished by addition of $\mathrm{CoCl}_{2}(2.5$ $\mathrm{mM})$ or $\mathrm{CdCl}_{2}(50-200 \mu \mathrm{M})$ to the perfusion medium. In medium containing $3 \mathrm{~mm}$ calcium and $1 \mathrm{~mm}$ magnesium, many EPSPs exceeded threshold. Elevation of the magnesium concentration to $10 \mathrm{~mm}$ also reversibly blocked spontaneous synaptic potentials in most of the cells.

Excitatory amino acids dissolved in recording medium were applied to 53 retrogradely labeled neurons by pressure ejection from a micropipet. Glutamate (10-50 $\mu \mathrm{M})$ and aspartate $(20-$ $200 \mu \mathrm{M}$ ), as well as the synthetic agonists $N$-methyl-D-aspartate (NMDA, 10-200 $\mu \mathrm{M})$, quisqualate $(0.5-5 \mu \mathrm{M})$, and kainate (5$20 \mu \mathrm{M})$, produced rapid depolarizations in every neuron tested (Figs. 9-13). Control application of recording medium alone
Figure 12. Effect of $\gamma$-D-glutamylglycine on the responses of a corticocollicular neuron to $N$-methyl-Daspartate, kainate, and quisqualate. Responses of the cell to 1 sec applications of $20 \mu \mathrm{M}$ NMDA, $5 \mu \mathrm{M}$ kainate, and $0.5 \mu \mathrm{M}$ quisqualate are shown before (top row of traces), during (middle row), and after (bottom row) superfusion of the culture with $0.5 \mathrm{~mm}$ DGG. The culture was prepared from a 7-d-old animal and the recording was obtained after $25 \mathrm{~d}$ in vitro.
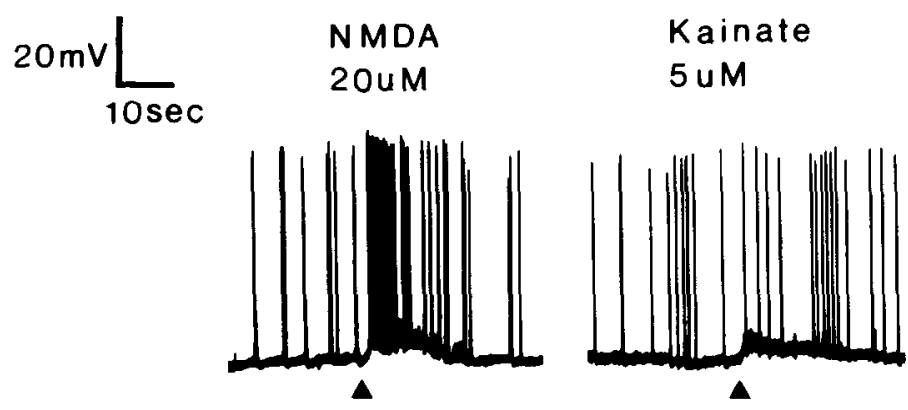

$D G G$

$0.5 \mathrm{mM}$
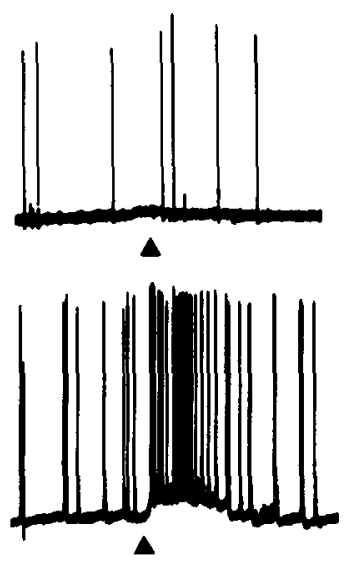

\section{Kainate \\ $5 \cup \mathrm{M}$}

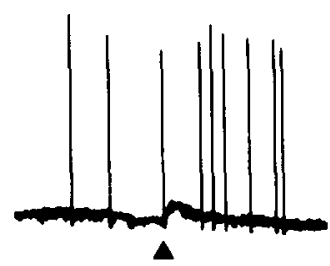

Quisqualate
0.5 uM

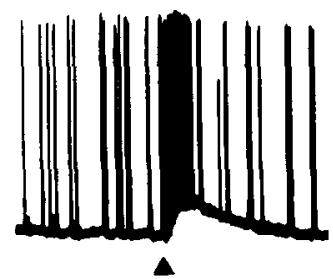

$\Delta$
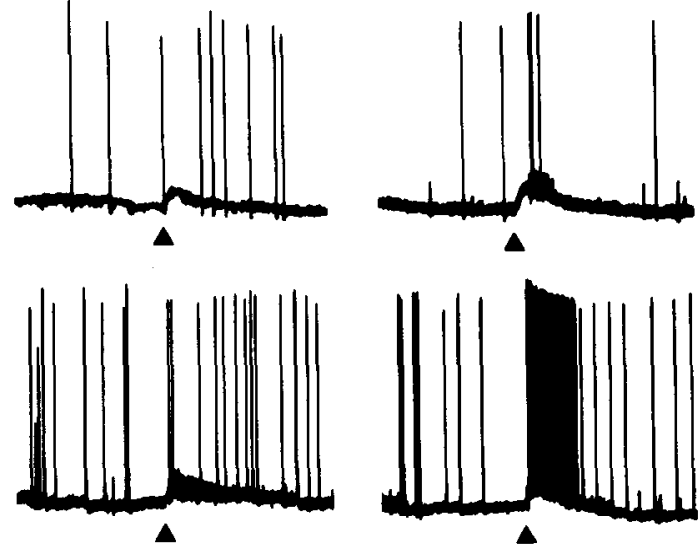

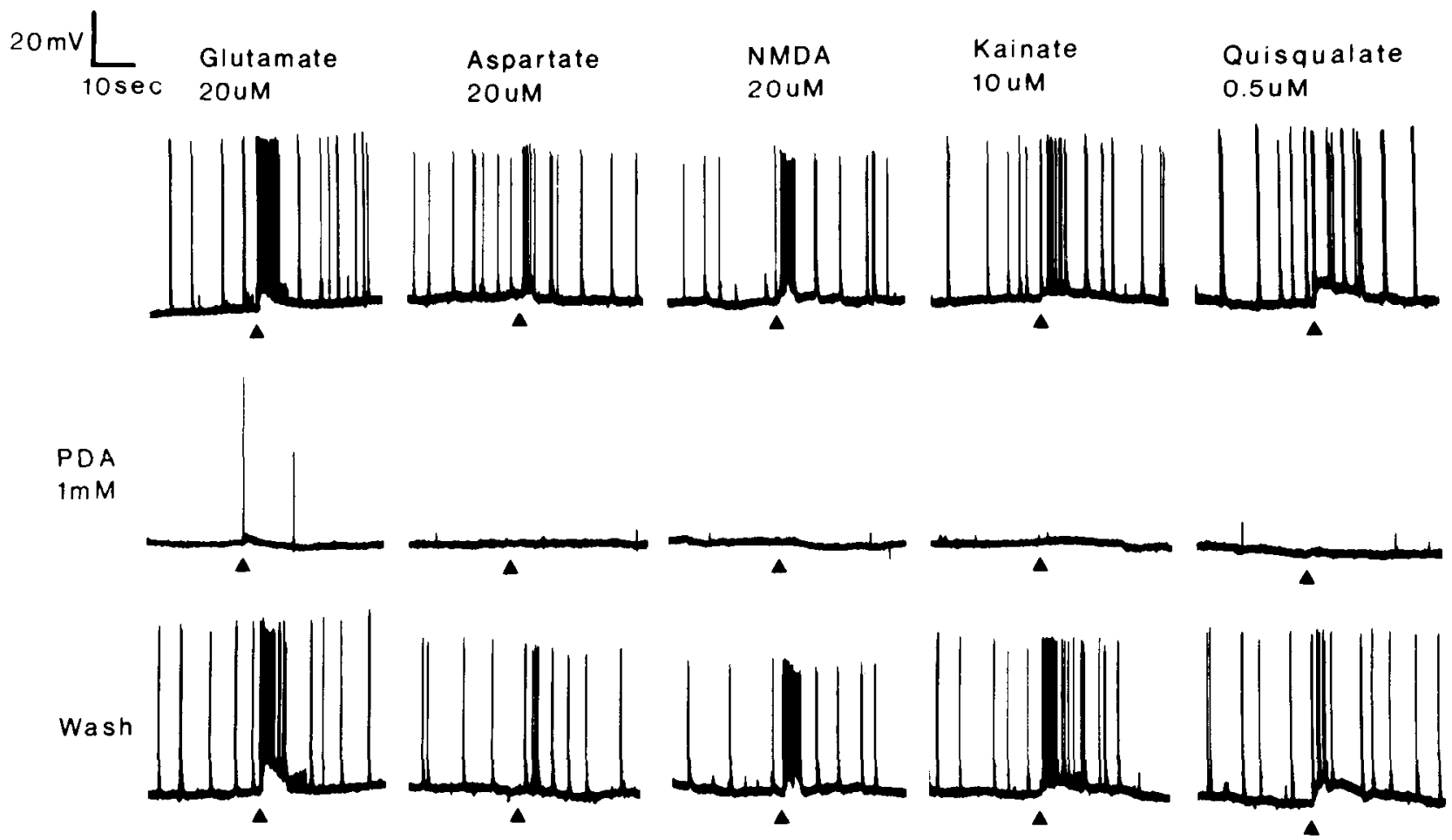

Figure 13. Effect of cis-2,3-piperidine dicarboxylic acid on the responses of a corticocollicular neuron to excitatory amino acids. Responses of the cell to $1 \mathrm{sec}$ applications of $20 \mu \mathrm{M}$ glutamate, $20 \mu \mathrm{M}$ aspartate, $20 \mu \mathrm{M}$ NMDA, $10 \mu \mathrm{M}$ kainate, and $0.5 \mu \mathrm{M}$ quisqualate are shown before (top row of traces), during (middle row), and after (bottom row) superfusion of the culture with 1 mM PDA. The culture was prepared from an 8-d-old animal and the recording was obtained after $21 \mathrm{~d}$ in vitro.

had no effect. Application of excitatory compounds also produced a transient increase in the frequency of EPSPs and IPSPs recorded in most cells. To determine whether the depolarizing responses to excitatory amino acids were due to direct excitation of the impaled neuron or solely to summation of EPSPs, we blocked synaptic transmission with $\mathrm{MgCl}_{2}$ or $\mathrm{CdCl}_{2}$. Figure $9 \mathrm{~A}$ shows recordings from a cell that exhibited suprathreshold EPSPs. The addition of $10 \mathrm{mM} \mathrm{MgCl}_{2}$ to the perfusion medium greatly reduced the frequency and amplitude of the spontaneous EPSPs in this cell. Nevertheless, application of each of the 5 agonists in the presence of high magnesium elicited strong depolarizations, indicating that the agonists were acting directly on this neuron. In spinal cord neurons, the current evoked by NMDA is reduced by $\mathrm{Mg}^{2+}$ and to a much lesser degree by $\mathrm{Cd}^{2+}$ (Mayer and Westbrook, 1985). Cortical cells superfused with $10 \mathrm{~mm}$ $\mathrm{MgCl}_{2}$ were depolarized by high concentrations of NMDA (100$200 \mu \mathrm{M})$ but not by lower concentrations $(10-20 \mu \mathrm{M})$ that were routinely effective in control medium $\left(3 \mathrm{mM} \mathrm{Ca}^{2+} / 1 \mathrm{mM} \mathrm{Mg}^{2+}\right)$. Sensitivity to glutamate and aspartate was also somewhat diminished in $10 \mathrm{mM} \mathrm{MgCl}_{2}$ but responses to quisqualate and kainate were not affected. Cadmium chloride at $200 \mu \mathrm{M}$ completely blocked synaptic potentials but did not antagonize responses to any of the excitatory compounds (data not shown).

We tested 5 antagonists of excitatory amino acid receptors for their ability to block responses to each of the 5 agonists (see Discussion). The compound 2-amino-5-phosphonovaleric acid (APV, 20-50 $\mu \mathrm{M}$; Davies and Watkins, 1982) had no effect on depolarizations produced by quisqualate or kainate, but it completely antagonized 10-200 $\mu \mathrm{M}$ NMDA (Fig. 10) and aspartate. Responses to low concentrations of glutamate were also diminished by APV (Fig. 11). Kynurenic acid (Ganong et al., 1983; Jahr and Jessell, 1985), cis-2,3-piperidine dicarboxylic acid (PDA; Davies et al., 1981) and $\gamma$-D-glutamyl glycine (DGG; Davies and Watkins, 1981) antagonized the depolarizing re- sponses to all 5 of the agonists. Partial blockade was obtained using 250-500 $\mu \mathrm{M}$ kynurenic acid, PDA, or DGG (Figs. 10, 12) and complete antagonism occurred at $1 \mathrm{~mm}$ (Figs. 9, 13). Addition of each of these 3 compounds at $1 \mathrm{~mm}$ to the perfusion medium also reversibly eliminated spontaneous synaptic activity. Glutamate diethyl ester (GDEE; Davies and Watkins, 1979; McLennan and Lodge, 1979) at concentrations up to $1 \mathrm{~mm}$ had no effect on responses to any of the agonists (Fig. 10; other data not shown) and did not alter spontaneous synaptic potentials.

Finally, in several experiments we recorded from retrogradely labeled neurons with electrodes containing the fluorescent dye Lucifer Yellow, which was injected iontophoretically to visualize the cell and its neurites. Each of the dye-filled neurons possessed 3-6 branching processes that extended 100-500 $\mu \mathrm{m}$ from the cell soma (Fig. 14, A, C). At high magnification, processes that resembled axons and dendrites could be distinguished (Fig. 14E). Dendritic processcs arose from a thick basc and possessed numerous short $(1-2 \mu \mathrm{m})$ spines along most of their length. Each cell had a single axonlike fiber that was thinner than the rest of the processes and that did not bear any spines. Although several of the dye-filled neurons clearly resembled pyramidal cells in their overall morphology, most of the cells were multipolar in appearance.

\section{Discussion}

Dissociated cell cultures of neocortical neurons have been prepared previously from embryonic animals (Dichter, 1978; Romijn et al., 1982; Swaiman et al., 1982; Thomas, 1985; Yavin and Yavin, 1977). The present study demonstrates that cortical neurons from young rats, $1-15 \mathrm{~d}$ of age, survive in culture and exhibit many differentiated properties. Several lines of evidence suggest that a number of distinct subpopulations of cortical neurons are present in these cultures. Approximately 20-25\% of all neurons possessed immunoreactivity for GAD, the en- 

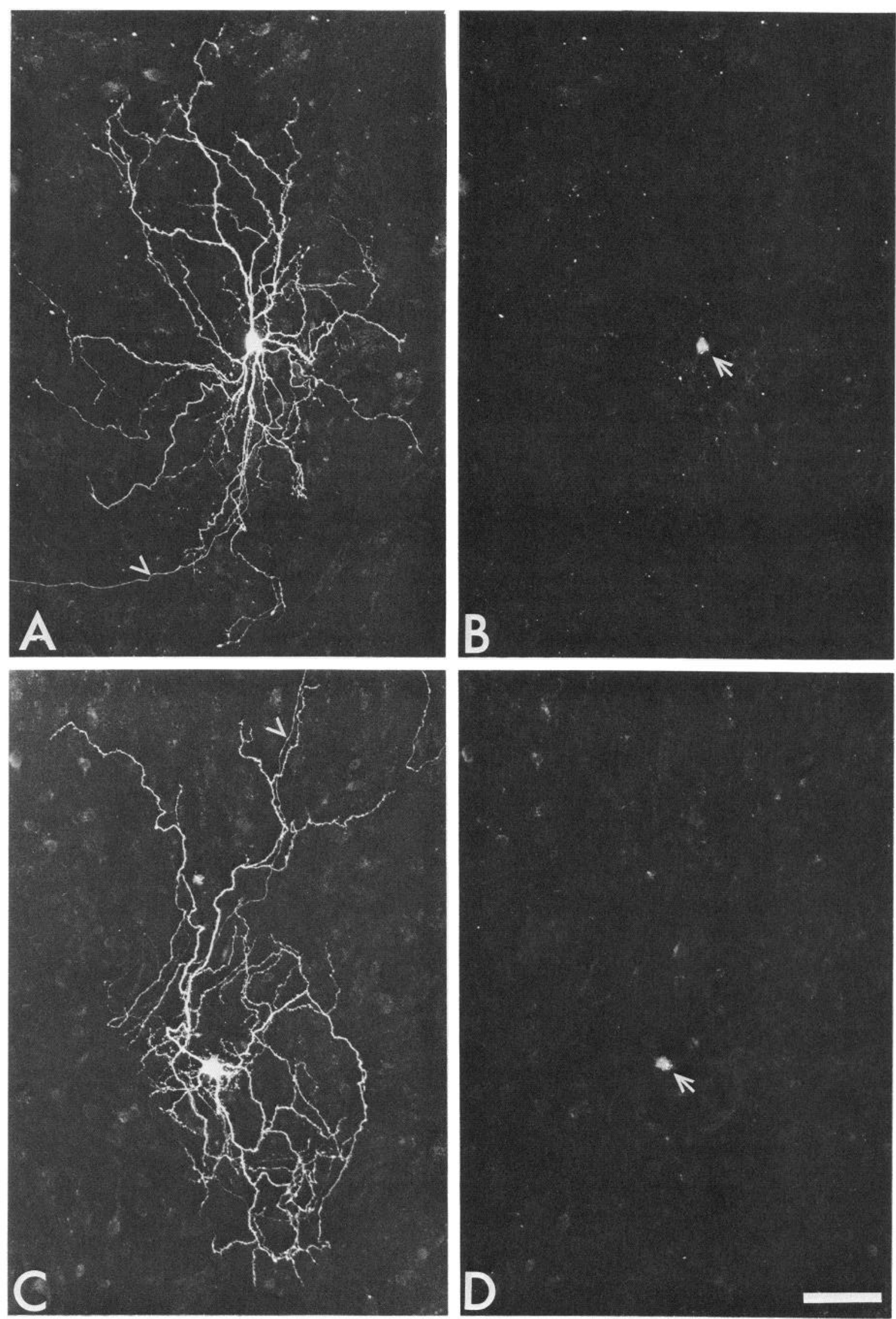

Figure 14. Fluorescence photomicrographs of 2 corticocollicular neurons that were injected with Lucifer Yellow after $42(A$ and $B)$ and $51(C$ and $D) \mathrm{d}$ in culture. $B$ and $D$, Fluorescence photomicrographs taken with a rhodamine filter set to visualize the fluorescent latex microspheres. 


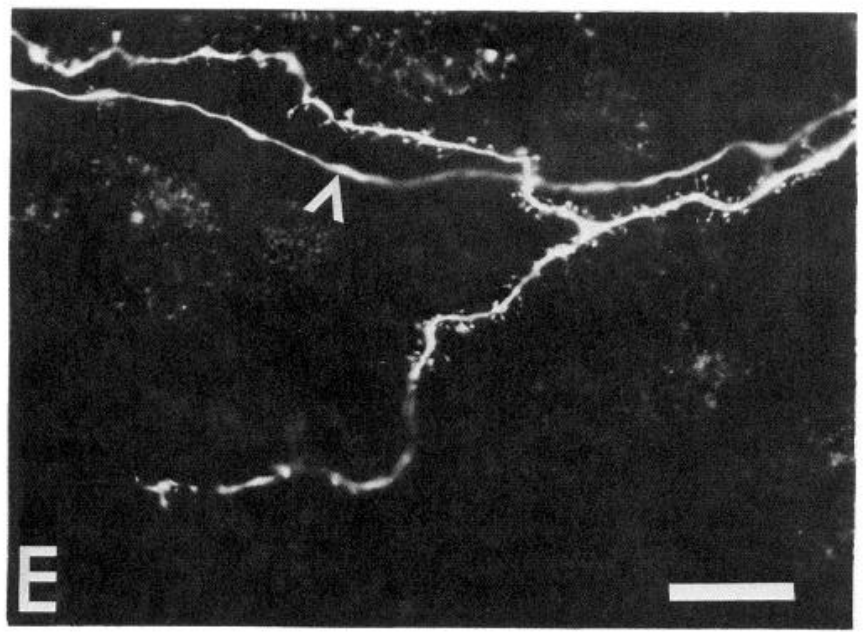

$\longleftarrow$

Arrows indicate the labeled cells. $A, C$, and $E$, Fluorescence photomicrographs of the same field taken with a filter set for Lucifer Yellow. Arrowheads indicate the axon of each cell. $E$, High-magnification photomicrograph of processes from the cell shown in $C$ and $D$. This photomicrograph was taken near the arrowhead in $C$. Numerous spines can be seen along the dendrite. $A$ and $B$, Culture prepared from a 8 -d-old animal. This cell has a distinctly pyramidal morphology. $C$ and $D$, Culture prepared from a 7-d-old animal. Although one dendrite of this neuron is prominent, the cell body appears multipolar. Bar: $A-D, 75$ $\mu \mathrm{m} ; E, 15 \mu \mathrm{m}$.

zyme that converts glutamate to GABA. Earlier work has shown that cortical cells in culture synthesize GABA (Hauser et al., 1980; Snodgrass et al., 1980; Thomas, 1985) and that neurons exhibiting GAD-IR also accumulate radioactive GABA from the culture medium (Neale et al., 1983). In embryonic cultures of the whole cerebral cortex, Neale et al. (1983) found that $12 \%$ of the neurons stained for GAD-IR and accumulated ${ }^{3} \mathrm{H}-\mathrm{GABA}$, while White et al. (1980) obtained 30-50\% labeling of neurons with ${ }^{3} \mathrm{H}-\mathrm{GABA}$. In the cerebral cortex in vivo, roughly $10-20 \%$ of all neurons exhibit GAD-IR (Schmechel et al., 1984).

Immunoreactivity for ChAT, the enzyme that synthesizes Ach, has been localized in vivo to a population of bipolar neurons in the rat cerebral cortex comprising 1-3\% of all cells (Eckenstein and Thoenen, 1983; Houser et al., 1983). Antiserum to VIP also stains cortical neurons with bipolar morphology that make up $2-3 \%$ of the total neuronal population (Connor and Peters, 1984; Fuxe et al., 1977; McDonald et al., 1982). Recently, coexistence of VIP-IR in over $80 \%$ of the ChAT-positive neurons has been demonstrated (Eckenstein and Baughman, 1984). Synthesis of $\mathrm{ACh}$ has been detected in cultures of embryonic cerebral cortex (Snodgrass et al., 1980; Swaiman et al., 1982; Thomas, 1985; Yavin, 1976), but localization of ChAT-IR and VIP-IR has not been reported. We find that $2-3 \%$ of all neurons in our cultures exhibit VIP-IR and $2-3 \%$ stain for ChAT. We have not investigated whether ChAT and VIP are coexpressed by cells in culture.

To identify specific populations of living cortical neurons in culture, we prelabeled the cells in vivo by retrograde transport of fluorescent latex microspheres (Katz et al., 1984). The present investigation concentrated on the neurons in layer $\mathrm{V}$ of the visual cortex that project to the superior colliculus, but we have also used these methods to identify in culture the neurons in layer VI that innervate the lateral geniculate nucleus (J. E. Huettner and R. W. Baughman, unpublished observations) and cortical neurons that project across the corpus callosum to the contralateral hemisphere (Huettner and Baughman, 1984; Nerbonne et al., 1985). Other investigators have used a variety of different retrogradely transported markers to identify spinal motor neurons (Calof and Reichardt, 1984; Eagleson and Bennett, 1983; Okun, 1981; Role et al., 1985) and retinal ganglion cells (Armson and Bennett, 1983; Leifer et al., 1984; Sarthy et al., 1983) in culture. These compounds, which include the dyes True blue, Granular Blue, and conjugates of Lucifer Yellow or FITC with HRP or wheat germ agglutinin, usually fade or are lost from cells after only a few days in culture. In addition, the blue dyes require UV light for excitation (Bentivoglio et al., 1979). Fluorescent microspheres, on the other hand, do not bleach rapidly, and retrogradely labeled neurons can be identified in vitro for many weeks. Visualization of the microspheres with $510-560 \mathrm{~nm}$ light, even for extended periods of time, is apparently harmless to living cells.

The morphology of retrogradely labeled layer $\mathrm{V}$ neurons was examined at both the light- and electron-microscopic level. The neurons in layer $\mathrm{V}$ of visual cortex that project to the superior colliculus are large pyramidal cells (Sefton et al., 1981). Pyramidal neurons in vivo are distinguished from other cell types by the shape of their somas and by their apical dendrite that extends radially through the cortex toward the pia (Feldman, 1984; Parnavelas et al., 1977). Dendritic spines are found on both the apical dendrite and the smaller basal dendrites of all pyramidal cells. When cells are dissociated and grown in culture, it is more difficult to classify their morphology (Banker and Cowan, 1979). In a study of embryonic cortical cultures, Kriegstein and Dichter (1983) classified Lucifer Yellow-filled cells as either pyramidal, fusiform, or multipolar. Neurons were considered to be pyramidal if they had spiny dendrites, if their cell body had a triangular profile, and if one of their dendrites was more prominent than the rest. In the present investigation, 18 layer $\mathrm{V}$ neurons were injected with Lucifer Yellow. Each cell exhibited a single thin axonlike fiber and 3-6 thicker, spiny dendrites. Several neurons had triangular cell bodies, but only 5 cells appeared distinctly pyramidal. The morphology of the remaining 13 cells was multipolar. At the ultrastructural level, mature neurons in culture bore the full complement of organelles found in vivo. Dendrites arose from the cell body as gradual taperings of the perikaryal cytoplasm and contained numerous polyribosomes. In a study of embryonic hippocampal neurons in culture, Bartlett and Banker $(1984 a, b)$ observed polyribosomes in dendrites but not in presumptive axons. These authors also found that morphological differentiation of axonal and dendritic processes occurred in neurons that did not contact any other cell type, suggesting that the development of axons and dendrites is an intrinsic property of the neurons (Bartlett and Banker, 1984a).

Most cortical neurons in vivo are excited by glutamate and aspartate (Hayashi, 1954; Krnjevic and Phillis, 1963). In culture, all of the neurons that we tested, including 53 labeled layer $\mathrm{V}$ cells and many unlabeled neurons, were depolarized by glutamate and aspartate, and by the synthetic agonists NMDA, kainate, and quisqualate. Recent pharmacological studies have provided evidence that excitatory amino acids act on more than one receptor site (Davies et al., 1982; Foster and Fagg, 1984; Watkins and Evans, 1981). In agreement with earlier work (Collingridge et al., 1983; Davies et al., 1981b; Rothman and Samaie, 1985), we found that APV selectively antagonized responses to NMDA and aspartate. APV also reduced responses to low concentrations of glutamate, but did not alter depolarizations due to kainate or quisqualate. Three other antagonistskynurenate, PDA, and DGG-blocked responses to all 5 of the agonists. Kynurenate and PDA are known to antagonize responses to NMDA, kainate, and quisqualate in a number of systems (Collingridge et al., 1983; Davies et al., 1981a; Ganong et al., 1983; Jahr and Jessell, 1985; Perkins and Stone, 1982). DGG is often found to diminish responses to NMDA and kain- 
ate selectively relative to responses elicited by quisqualate (Davies and Watkins, 1981; Rothman and Samaie, 1985). In some cases, however, DGG at higher concentrations can also block responses to quisqualate (Collingridge et al., 1983; Crunelli et al., 1983; O'Brien, 1985). In our hands, 1 mM DGG was necessary to achieve complete antagonism of NMDA and kainate depolarizations, and at this concentration, responses to quisqualate, glutamate, and aspartate were also abolished. A final antagonist, GDEE, is known to selectively block responses of spinal cord neurons in vivo to quisqualate (Davies and Watkins, 1979; McLennan and Lodge, 1979). In slices of cortex (Hori et al., 1982) and hippocampus (Collingridge et al., 1983), however, GDEE is much less effective. We could not discern any effect of GDEE at concentrations up to $1 \mathrm{~mm}$ on responses to the agonists that we tested.

The results of our pharmacological experiments provide strong evidence that corticocollicular neurons in culture express both NMDA-type and non-NMDA receptors for excitatory amino acids. In the spinal cord, the differential sensitivity of kainate and quisqualate responses to antagonism by DGG (Davies and Watkins, 1981) and GDEE (Davies and Watkins, 1979; McLennan and Lodge, 1979) has been proposed as evidence for 2 subtypes of non-NMDA receptors (Watkins and Evans, 1981). We find that GDEE is without effect on cortical neurons in culture and that responses to both kainate and quisqualate are antagonized by DGG. These results are consistent with the presence of a single type of non-NMDA receptor that is activated by both kainate and quisqualate (O'Brien, 1985).

The primary motivation for using postnatal animals in this study was that retrograde labeling of specific cell populations would be difficult or impossible to achieve in the embryo. A second reason for using older animals was that the neocortex of embryonic rodents is relatively immature. While most cells destined to be neurons have undergone their final mitosis by embryonic day 21 (Berry and Rogers, 1965), many of the attributes of adult neurons are not fully expressed until 2-3 weeks after birth (Chronwall and Wolff, 1980; Ivy and Killackey, 1981; McDonald et al., 1982). At present, it is not known whether each class of cortical neurons is composed of cells whose fate is fully determined early in development, or whether the ultimate fate of any given neuron depends upon interactions with the local environment during migration and differentiation (Caviness, 1982; Jensen and Killackey, 1984; Jones et al., 1982; McConnell, 1985) or upon interactions with the targets that it innervates. Cortical neurons obtained from animals 1-2 weeks of age, such as thosc used in the present study, have been exposed to normal environmental influences for a much longer period of time than have embryonic cells. As a result, these older neurons may be more firmly established on a particular developmental course.

This study has shown that neurons from the visual cortex of postnatal rats, up to $15 \mathrm{~d}$ of age, survive in dissociated culture, regenerate processes, and form synaptic connections. Specific subpopulations of living neurons were identified in long-term culture by labeling the cells in vivo with retrogradely transported fluorescent latex microspheres. Identified corticocollicular neurons exhibited many normal morphological and physiological properties, including both NMDA and non-NMDA receptors for excitatory amino acids. Antisera to GAD, ChAT, and VIP labeled subpopulations of neurons in culture that were roughly proportional to the percentage of cells that stain for these antigens in vivo. Corticocollicular neurons were not stained by these 3 antisera. Further experiments on the electrophysiological characterization (Nerbonne et al., 1985) and synaptic pharmacology (Huettner and Baughman, 1985) of identified cortical neurons are in progress.

\section{References}

Anderton, B. H., R. Thorpe, J. Cohen, S. Selvendran, and P. Woodhams (1980) Specific neuronal localization by immunofluorescence of 10 nm filament polypeptides. J. Neurocytol. 9: 835-844.

Antanitus, D. S., B. H. Choi, and L. W. Lapham (1975) Immunofluorescence staining of astrocytes in vitro using antiserum to glial fibrillary acidic protein. Brain Res. 89: 363-367.

Armson, P. F., and M. R. Bennett (1983) Neonatal retinal ganglion cell cultures of high purity: Effect of superior colliculus on their survival. Neurosci. Lett. 38: 181-186.

Bader, C. R., P. R. MacLeish, and E. A. Schwartz (1978) Response to light of solitary rod photoreceptors isolated from tiger salamander retina. Proc. Natl. Acad. Sci. USA 75: 3507-3511.

Banker, G. A., and W. M. Cowan (1979) Further observations on hippocampal neurons in dispersed cell culture. J. Comp. Neurol. 187: 469-494.

Bartlett, W. P., and G. A. Banker (1984a) An electron microscopic study of the development of axons and dendrites by hippocampal neurons in culture. I. Cells which develop without intercellular contacts. J. Neurosci. 4: 1944-1953.

Bartlett, W. P., and G. A. Banker (1984b) An electron microscopic study of the development of axons and dendrites by hippocampal neurons in culture. II. Synaptic relationships. J. Neurosci. 4: 19541965.

Baughman, R., and C. D. Gilbert (1981) Aspartate and glutamate as possible neurotransmitters in the visual cortex. J. Neurosci. 1: 427439.

Bentivoglio, M., H. G. J. M. Kuypers, C. E. Catsman-Berrevoets, and O. Dann (1979) Fluorescent retrograde neuronal labeling in rat by means of substances binding specifically to adenine-thymine rich DN $\Lambda$. Neurosci. Lett. 12: 235-240.

Berry, M., and A. W. Rogers (1965) The migration of neuroblasts in the developing cerebral corlex. J. Anal. 99: 691-709.

Bignami, A., L. F. Eng, D. Dahl, and C. T. Uyeda (1972) Localization of the glial fibrillary acidic protein in astrocytes by immunofluorescence. Brain Res. 43: 429-435.

Bornstein, M. B. (1958) Reconstituted rat-tail collagen used as a substrate for tissue cultures on coverslips in Maximow slides and roller tubes. Lab. Invest. 7: 134.

Bray, D. (1970) Surface movements during the growth of single explanted neurons. Proc. Natl. Acad. Sci. USA 65:905-910.

Calof, A. L., and L. F. Reichardt (1984) Motoneurons purified by cell sorting respond to two distinct activities in myotube-conditioned medium. Dev. Biol. 106: 194-210.

Caviness, V. S., Jr. (1982) Neocortical histogenesis in normal and reeler mice: A developmental study based upon ${ }^{3} \mathrm{H}$-thymidine autoradiography. Dev. Brain Res. 4: 293-302.

Choi, D. W., and G. D. Fischbach (1981) GABA conductance of chick spinal cord and dorsal root ganglion neurons in cell culture. J. Neurophysiol. 45: 605-620.

Chronwall, B., and J. R. Wolff (1980) Prenatal and postnatal development of GABA-accumulating cells in the occipital neocortex of rat. J. Comp. Neurol. 190: 187-208.

Collingridge, G. L., S. J. Kehl, and H. McLennan (1983) The antagonism of amino acid-induced excitation of rat hippocampal CA1 neurones in vitro. J. Physiol. (Lond.) 334: 19-31.

Connor, J. R., and A. Peters (1984) Vasoactive intestinal polypeptideimmunoreactive neurons in rat visual cortex. Neuroscience 12: 10271044.

Crunelli, V., S. Forda, and J. S. Kelly (1983) Blockade of amino acidinduced depolarizations and inhibition of excitalory post-synaptic potentials in rat dentate gyrus. J. Physiol. (Lond.) 341: 627-640.

Davies, J., and J. C. Watkins (1979) Selective antagonism of amino acid induced and synaptic excitation in the cat spinal cord. J. Physiol. (Lond.) 297: 621-635.

Davies, J., and J. C. Watkins (1981) Differentiation of kainate and quisqualate receptors in the cat spinal cord by selective antagonism with $\gamma$-D(and L)-glutamylglycine. Brain Res. 206: 172-177.

Davies, J., and J. C. Watkins (1982) Actions of D and L forms of 2-amino-5-phosphonovalerate and 2-amino-4-phosphonobutyrate in the cat spinal cord. Brain Res. 235: 378-386.

Davies, J., R. H. Evans, A. A. Francis, A. W. Jones, and J. C. Watkins (1981a) Antagonism of excitatory amino acid-induced and synaptic 
excitation of spinal neurones by cis-2,3-piperidine dicarboxylate. J. Neurochem. 100: 1305-1307.

Davies, J., A. A. Francis, A. W. Jones, and J. C. Watkins (1981b) 2-Amino-5-phosphonovalerate (2APV), a potent and selective antagonist of amino acid-induced and synaptic excitation. Neurosci. Lett. 21: 77-81.

Davies, J., R. H. Evans, A. W. Jones, D. A. S. Smith, and J. C. Watkins (1982) Differential activation and blockade of excitatory amino acid receptors in the mammalian and amphibian central nervous systems. Comp. Biochem. Physiol. 72: 211-224.

Dichter, M. A. (1978) Rat cortical neurons in cell culture: culture methods, cell morphology, electrophysiology, and synapse formation. Brain Res. 149: 279-293.

Dräger, U. C., D. L. Edwards, and J. Kleinschmidt (1983) Neurofilaments contain $\alpha$-melanocyte-stimulating hormone ( $\alpha \mathrm{MSH})$-like immunoreactivity. Proc. Natl. Acad. Sci. USA 80: 6408-6412.

Eagleson, K. L., and M. R. Bennett (1983) Survival of purified motor neurones in vitro: Effects of skeletal muscle-conditioned medium. Neurosci. Lett. 38: 187-192.

Eckenstein, F., and H. Thoenen (1982) Production of specific antsera and monoclonal antibodies to choline acetyltransferase: Characterization and use for identification of cholinergic neurons. EMBO J. 1: 363-368.

Eckenstein, F., and H. Thoenen (1983) Cholinergic neurons in the rat cerebral cortex demonstrated by immunohistochemical localization of choline acetyltransferase. Neurosci. Lett. 36: 211-215.

Eckenstein, F. E., and R. W. Baughman (1984) Two types of cholinergic innervation in cortex, one co-localized with vasoactive intestinal polypeptide. Nature 309: 153-155.

Feldman, M. L. (1984) Morphology of the neocortical pyramidal neuron. In Cerebral Cortex, Vol. 1, A. Peters and E. G. Jones, eds., pp. 123-200, Plenum, New York.

Fischbach, G. D., and P. G. Nelson (1977) Cell culture in neurobiology. In Handbook of Physiology, Sect. 1, The Nervous System, E. R. Kandel, ed., pp. 719-774, American Physiological Society, Bethesda, MD.

Fonnum, F. (1984) Glutamate: A neurotransmitter in mammalian brain. J. Neurochem. 42: 1-11.

Foster, A. C., and G. E. Fagg (1984) Acidic amino acid binding sites in mammalian neuronal membranes: Their characteristics and relationship to synaptic receptors. Brain Res. Rev. 7: 103-164.

Fuxe, K., T. Hökfelt, S. I. Said, and V. Mutt (1977) Vasoactive intestinal polypeptide and the nervous system: Immunohistochemical evidence for localization in central and peripheral neurons, particularly intracortical neurons of the cerebral cortex. Neurosci. Lett. 5: 241-246.

Ganong, A. H., T. H. Lanthorn, and C. W. Cotman (1983) Kynurenic acid inhibits synaptic and acidic amino acid-induced responses in the rat hippocampus and spinal cord. Brain Res. 273: 170-174.

Gilbert, C. D. (1983) Microcircuitry of the visual cortex. Annu. Rev. Neurosci. 6: 217-247.

Gilbert, C. D., and J. P. Kelly (1975) The projections of cells in different layers of the cat's visual cortex. J. Comp. Neurol. 163: 81106.

Gilbert, C. D., and T. N. Wiesel (1979) Morphology and intracortical projections of functionally characterized neurones in the cat visual cortex. Nature 280: 120-125.

Hamos, J. E., T. L. Davis, and P. Sterling (1983) Four types of neurons in layer IVab of cat cortical area 17 accumulate ${ }^{3} \mathrm{H}-\mathrm{GABA}$. J. Comp. Neurol. 217: 449-457.

Hauser, K., V. J. Balcar, and R. Bernasconi (1980) Development of GABA neurons in dissociated cell culture of rat cerebral cortex. Brain Res. Bull. (Suppl. 2) 5: 37-41.

Hayashi, T. (1954) Effects of sodium glutamate on the nervous system. Keio J. Med. 3: 183-192.

Hori, N., C. R. Auker, D. J. Braitman, and D. O. Carpenter (1982) Pharmacologic sensitivity of amino acid responses and synaptic activation of in vitro prepyriform neurons. J. Neurophysiol. 48: 12891301.

Houser, C. R., G. D. Crawford, R. P. Barber, P. M. Salvaterra, and J. E. Vaughn (1983) Organization and morphological characteristics of cholinergic neurons: An immunohistochemical study with a monoclonal antibody to choline acetyltransferase. Brain Res. 266: 97-119.

Houser, C. R., J. E. Vaughn, S. H. C. Hendry, E. G. Jones, and A. Peters
(1984) GABA neurons in the cerebral cortex. In Cerebral Cortex Vol. 2, E. G. Jones and A. Peters, eds., pp. 63-89, Plenum, New York.

Huettner, J. E., and R. W. Baughman (1984) Dissociated cell cultures prepared from the visual cortex of postnatal hooded rats. Soc. Neurosci. Abstr. 10: 165.

Huettner, J. E., and R. W. Baughman (1985) Response properties of identified cortical neurons in tissue culture to excitatory amino acid agonists and antagonists. Soc. Neurosci. Abstr. 11: 823.

Ivy, G. O., and H. P. Killackey (1981) The ontogeny of the distribution of callosal projection neurons in the rat parietal cortex. J. Comp. Neurol. 195: 367-389.

Jahr, C. E., and T. M. Jessell (1985) Synaptic transmission between dorsal root ganglion and dorsal horn neurons in culture: Antagonism of monosynaptic excitatory postsynaptic potentials and glutamate excitation by kynurenate. J. Neurosci. 5: 2281-2289.

Jensen, K. F., and H. P. Killackey (1984) Subcortical projections from ectopic neocortical neurons. Proc. Nati. Acad. Sci. USA 81: 964-968.

Jones, E. G., K. L. Valentino, and J. W. Fleshman (1982) Adjustments of connectivity in rat neocortex after prenatal destruction of precursor cells in layers II-IV. Dev. Brain Res. 2: 425-431.

Katz, L. E., A. Burkhalter, and W. J. Dreyer (1984) Fluorescent latex microspheres as a retrograde neuronal marker for in vivo and in vitro studies of visual cortex. Nature 310: 498-500.

Krieg, W. J. S. (1946) Connections of the cerebral cortex. I. The albino rat. A. Topography of cortical areas. J. Comp. Neurol. 84: 221-275.

Kriegstein, A. R., and M. A. Dichter (1983) Morphological classification of rat cortical neurons in cell culture. J. Neurosci. 3: 1634 1647.

Krnjevic, K., and J. W. Phillis (1963) Iontophoretic studies of neurones in the mammalian cerebral cortex. J. Physiol. (Lond.) 165: 274 304.

Lam, D. M. K. (1972) Biosynthesis of acetylcholine in turtle photoreceptors. Proc. Natl. Acad. Sci. USA 69: 1987-1991.

Landis, S. C. (1976) Rat sympathetic neurons and cardiac myocytes developing in microcultures: Correlation of the fine structure of endings with neurotransmitter function in single neurons. Proc. Natl. Acad. Sci. USA 73: 4220-4224.

Leifer, D., S. A. Lipton, C. J. Barnstable, and R. H. Masland (1984) Monoclonal antibody to Thy-1 enhances regeneration of processes by rat retinal ganglion cells in culture. Science 224: 303-306.

LeVay, S., and H. Sherk (1981) The visual claustrum of the cat. I. Structural connections. J. Neurosci. 1: 956-980.

Liem, R. K. H., S. H. Yen, G. D. Salomon, and M. L. Shelanski (1978) Intermediate filaments in nervous tissue. J. Cell Biol. 79: 637-645.

Mains, R. E., and P. H. Patterson (1973) Primary cultures of dissociated sympathetic neurons. I. Establishment of long-term growth in culture and studies of differentiated properties. J. Cell Biol. 59: 329_ 345.

Mayer, M. L., and G. L. Westbrook (1985) The action of N-methylD-aspartic acid on mouse spinal neurones in culture. J. Physiol. (Lond.) 361: 65-90.

McConnell, S. K. (1985) Migration and differentiation of cerebral cortical neurons after transplantation into the brains of ferrets. Science 229: $1268-1271$.

McDonald, J. K., J. G. Parnavelas, A. N. Karamanlidis, and N. Brecha (1982) The morphology and distribution of peptide-containing neurons in the adult and developing visual cortex of the rat. II. Vasoactive intestinal polypeptide. J. Neurocytol. 11: 825-837.

McLennan, H., and D. Lodge (1979) The antagonism of amino acidinduced excitation of spinal neurones in the cat. Brain Res. 169: 8390.

Miller, M. W., and B. A. Vogt (1984) Direct connections of rat visual cortex with sensory, motor and association cortices. J. Comp. Neurol. 226: 184-202.

Neale, E. A., W. H. Oertel, L. M. Bowers, and V. K. Weise (1983) Glutamate decarboxylase immunoreactivity and $\gamma-\left[{ }^{3} \mathrm{H}\right]$-aminobutyric acid accumulation within the same neurons in dissociated cell cultures of cerebral cortex. J. Neurosci. 3: 376-382.

Nerbonne, J. M., A. Burkhalter, and J. E. Huettner (1985) Electrophysiological characterization of identified, intrinsic cortical neurons in dissociated cell culture. Soc. Neurosci. Abstr. 11: 149.

O'Brien, R. (1985) Properties of identified motoneurons in culture. Ph.D. Thesis, Harvard University. 
Oertel, W. H., D. E. Schmechel, M. L. Tappaz, and I. J. Kopin (1981) Production of a specific antiserum to rat brain glutamic acid decarboxylase by injection of an antigen-antibody complex. Neuroscience 6: $2689-2700$.

Okun, L. M. (1981) Identification and isolation in vitro of neurons marked in situ by retrograde transport. In New Approaches in Developmental Neurobiology, pp. 109-121, Society for Neuroscience, Bethesda, MD.

O'Lague, P. H., D. D. Potter, and E. J. Furshpan (1978) Studies on rat sympathetic neurons developing in cell culture. I. Growth characteristics and electrophysiological properties. Dev. Biol. 67: 384403.

Parnavelas, J. G., A. R. Lieberman, and K. E. Webster (1977) Organization of neurons in the visual cortex, area 17, of the rat. J. Anat. 124: 305-322.

Parnavelas, J. G., R. A. Burne, and C. S. Lin (1983) Distribution and morphology of functionally identified neurons in the visual cortex of the rat. Brain Res. 261: 21-29.

Perkins, M. N., and T.W. Stone (1982) An iontophoretic investigation of the action of convulsant kynurenines and their interaction with the endogenous excitant quinolinic acid. Brain Res. 247: 184-187.

Peters, A. (1985) The visual cortex of the rat. In Cerebral Cortex, Vol. 3, A. Peters and E. G. Jones, eds., pp. 19-80, Plenum, New York.

Peters, A., S. L. Palay, and H. D. Webster (1976) The Fine Structure of the Nervous System, W. B. Saunders, Philadelphia, PA.

Phillips, H. J. (1973) Dye exclusion tests for cell viability. In Tissue Culture: Methods and Applications, P. F. J. Kruse and M. K. Patterson, eds., pp. 406-408, Academic, New York.

Raff, M. C., K. L. Fields, S. I. Hakomori, R. Mirsky, R. M. Pruss, and J. Winter (1979) Cell-type-specific markers for distinguishing and studying neurons and the major classes of glial cells in culture. Brain Res. 174: 283-308.

Ribak, C. E. (1978) Aspinous and sparsely-spinous stellate neurons in the visual cortex of rats contain glutamic acid decarboxylase. J. Neurocytol. 7: 461-478.

Role, L. W., V. R. Matossian, R. J. O'Brien, and G. D. Fischbach (1985) On the mechanism of acetylcholine receptor accumulation at newly. formed synapses on chick myotubes. J. Neurosci. 5: 2197-2204.

Romijn, H. J., A. M. M. C. Habets, M. T. Mud, and P. S. Wolters (1982) Nerve outgrowth, synaptogenesis and bioelectric activity in fetal rat cerebral cortex tissue cultured in serum-free, chemically defined medium. Dev. Brain Res. 2: 583-589.

Rothman, S. M., and M. Samaie (1985) Physiology of excitatory synaptic transmission in cultures of dissociated rat hippocampus. J. Neurophysiol. 54: 701-713.
Sarthy, P. V., B. M. Curtis, and W. A. Catterall (1983) Retrograde labeling, enrichment and characterization of retinal ganglion cells from the neonatal rat. J. Neurosci. 3: 2532-2544.

Schlaepfer, W. W., and L. A. Freeman (1978) Neurofilament proteins of rat peripheral nerve and spinal cord. J. Cell Biol. 78: 653-662.

Schmechel, D. E., B. G. Vickrey, D. Fitzpatrick, and R. P. Elde (1984) GABAergic neurons of mammalian cerebral cortex: Widespread subclass defined by somatostatin content. Neurosci. Lett. 47: 227-232.

Sefton, A. J., A. Mackay-Sim, L. A. Baur, and L. J. Cottee (1981) Cortical projections to visual centers in the rat: An HRP study. Brain Res. 215: 1-13.

Snodgrass, S. R., W. F. White, B. Biales, and M. Dichter (1980) Biochemical correlates of GABA function in rat cortical neurons in culture. Brain Res. 190: 123-138.

Somogyi, P., A. J. Hodgson, A. D. Smith, M. G. Nunzi, A. Gorio, and J. Y. Wu (1984) Different populations of GABAergic neurons in the visual cortex and hippocampus of cat contain somatostatin- or cholecystokinin-immunoreactive material. J. Neurosci. 4: 2590-2603.

Stewart, W. W. (1981) Lucifer dyes-highly fluorescent dyes for biological tracing. Nature 292: 17-21.

Streit, P. (1984) Glutamate and aspartate as transmitter candidates for systems of the cerebral cortex. In Cerebral Cortex, Vol. 2, E. G. Jones and A. Peters, eds., pp. 119-143, Plenum, New York.

Swaiman, K. F., E. F. Neale, S. C. Fitzgerald, and P. G. Nelson (1982) A method of large-scale production of mouse brain cortical cultures. Dev. Brain Res. 3: 361-369.

Thomas, W. E. (1985) Synthesis of acetylcholine and $\gamma$-aminobutyric acid by dissociated cerebral cortical cells in vitro. Brain Res. 332: 79-89.

Townes-Anderson, E., P. R. MacLeish, and E. Raviola (1985) Rod cells dissociated from mature salamander retina: Ultrastructure and uptake of horseradish peroxidase. J. Cell Biol. 100: 175-188.

Watkins, J. C., and R. H. Evans (1981) Excitatory amino acid transmitters. Annu. Rev. Pharmacol. Toxicol. 21: 165-204.

White, W. F., S. R. Snodgrass, and M. Dichter (1980) Identification of GABA neurons in rat cortical cultures by GABA uptake autoradiography. Brain Res. 190: 139-152.

Yavin, E. (1976) Regulation of phospholipid metabolism in differentiating cells from rat brain cerebral hemispheres in culture. J. Biol. Chem. 251: 1392-1397.

Yavin, Z., and E. Yavin (1977) Synaptogenesis and myelinogenesis in dissociated cerebral cells from rat embryo on polylysine coated surfaces. Exp. Brain Res. 29: 137-147. 